\title{
El papel del capital multinacional en los procesos de integración regional (ALALC y Mercosur)
}

\section{The role of multinational capital in the regional integration processes (LAFTA and Mercosur)}

\author{
SiLvina María Romano*
}

\begin{abstract}
This article analyses the role of direct foreign investment in general, and of multinational capital in particular, in the integration process crystallised by the Asociación Latinoamericana de Libre Comercio (Latin American Free Trade Association, LAFTA, 1960) and the Mercado Común del Sur (Southern Common Market, Mercosur, 1991). We revise the theoretical positions of greater weight in the area of economic integration at a regional level, both in postwar as well as in current times. We also link them with the statistics of direct foreign investment and the strategies of multinational enterprises provided by the United Nations (UN), the Economic Commission for Latin America and the Caribbean (ECLAC) and the Latin American Free Trade Association (LAFTA) to understand the incidence of the mechanisms that promote the central economies in the peripheral spaces in Latin America.
\end{abstract}

Keywords: multinational capital, LAFTA, Mercosur.

\section{Resumen}

En este artículo se analiza la función de la inversión extranjera directa en general, y del capital multinacional en particular, en el proceso de integración cristalizado en la Asociación Latinoamericana de Libre Comercio (alalc, 1960) y en el Mercado Común del Sur (Mercosur, 1991). Se revisan las posturas teóricas de mayor peso en materia de integración económica en el ámbito regional, tanto en la posguerra como en la actualidad, y se articulan con estadísticas sobre inversión extranjera directa y estrategias de las empresas multinacionales provistas por la ONU, la CEPAL y la ALALC para comprender la incidencia de los mecanismos que promueven las economías centrales en los espacios periféricos como América Latina.

Palabras clave: capital multinacional, ALALC, Mercosur.

* Consejo Nacional de Investigaciones Científicas y Tecnológicas, Córdoba, Argentina. Correo-e: celesteromano@yahoo.com.ar. 


\section{Introducción}

En el periodo posterior a la segunda Guerra Mundial, las economías latinoamericanas tuvieron serias limitaciones con respecto a su inserción en el sistema internacional, debido a su estructura básicamente agroexportadora y al escaso desarrollo industrial que conducían a permanentes desequilibrios en las balanzas de pagos nacionales. Esta situación se agravó con el creciente deterioro de los términos de intercambio de las materias primas, en contraste con los productos manufacturados en el mercado mundial (Thorp, 2000), al tiempo que disminuyeron las exportaciones hacia las economías centrales en orden al mayor intercambio entre países industrializados, tanto de materias primas como de manufacturas (Ferrer, 1976).

En este contexto desfavorable para el desarrollo de las economías latinoamericanas, la Comisión Económica para América Latina (CEPAL) impulsó un proyecto de integración regional, con el objetivo de aumentar el comercio, lograr el desarrollo de una industria complementaria y competitiva internacionalmente y negociar como bloque frente a los países industrializados. Uno de los factores fundamentales para lograr tales metas era la afluencia de capitales hacia la región (CEPAL, 1959). No obstante las expectativas de la CEPAL en lo relativo a la integración y al desarrollo industrial, los postulados estructuralistas no lograron plasmarse en las economías de la región. Esto condujo a una importante revisión teórica: se desarrolló una corriente crítica al interior de la misma CEPAL, al tiempo que se fue constituyendo una línea de pensamiento que tendió a radicalizar dichos postulados, denominada escuela de la dependencia (Beigel, 2006). A principios de los setenta hubo un retorno a la economía neoclásica, sustentado por el advenimiento de una importante crisis económico-financiera originada en los países desarrollados, que luego se expandió hacia la periferia (Tamames, 1990). El endeudamiento de América Latina, en parte ocasionado a partir de la mencionada crisis, permitió que se afianzaran las políticas neoliberales basadas en premisas neoconservadoras, promovidas especialmente por el Banco Mundial y los intelectuales que contribuyeron a confeccionar y legitimar el Consenso de Washington (Kuntz, 2005: 152).

Frente a esta realidad se generaron nuevas lecturas sobre la integración y el desarrollo, cobrando mayor peso el neoestructuralismo, que si bien retoma parte importante de los postulados 
estructuralistas, plantea la necesidad de adaptarse al contexto internacional de la manera más provechosa posible para América Latina (Fuentes, 1994; Ocampo 1998; CEPAL, 2007), aunque ello implique resignar algunos de los objetivos más preciados del pensamiento cepalino-crítico de los sesenta y principios de los setenta.

En este trabajo abordamos el rol de la inversión extranjera directa, en general, y del capital multinacional, en particular, en el proceso de integración cristalizado en la Asociación Latinoamericana de Libre Comercio (ALALC) y en el actual Mercado Común del Sur (Mercosur). Para ello retomamos las posturas teóricas de mayor peso en materia de integración económica en el ámbito regional, tanto en la posguerra (estructuralismo cepalino y escuela de la dependencia) como en la actualidad (postulados neoclásicos y neoestructuralismo), articulándolas con estadísticas sobre inversión extranjera directa y estrategias de las empresas multinacionales provistas por la ONU, la CEPAL, la ALALC, así como bibliografía especializada, con el objetivo de comprender la incidencia de los mecanismos promovidos por las economías centrales en los espacios periféricos, como América Latina. Vale aclarar que en especial tenemos en cuenta al capital multinacional de origen norteamericano, debido a la influencia del gobierno y el sector privado estadounidense en América Latina en los procesos de integración y en las economías de la región en general.

\section{Capital multinacional, desarrollo, subdesarrollo y el proyecto de integración de la ALALC}

Antes de referirnos específicamente al rol del capital multinacional en el proceso de integración de América Latina en la posguerra, hacemos una breve referencia al contexto en el cual comprendemos este concepto. La idea de capital multinacional se enmarca en el desarrollo del capitalismo, el cual tiene sus orígenes en la etapa monopólica iniciada por la conformación de los cárteles y trusts a fines del siglo XIX y principios del XX. ${ }^{1}$ De este

${ }^{1}$ Los trabajos de Hobson, Hilferding y Lenin constituyen algunos de los íconos acerca de la teoría del imperialismo entendiendo este fenómeno como intrínseco al capitalismo. Para dar cuenta de la postura contraria, es interesante la perspectiva de Schumpeter (1965) acerca del imperialismo como atavismo social. Atendiendo los objetivos del presente trabajo se retoman los postulados del imperialismo como etapa superior del capitalismo de modo indirecto, ya que nos basamos en las aproximaciones de imperialismo y capital monopólico reelaborados desde el neomarxismo, donde algunos trabajos clave son Baran y Sweezy (1974), Sweezy (1973) y Huberman y Sweezy (1973). 
modo, las grandes empresas en lugar de competir entre ellas concibieron que la integración vertical (que implica la articulación de las diferentes etapas del proceso productivo) y la horizontal (que requiere el control de un producto o un tipo de producto por una empresa) de la economía, representaba una alternativa mucho más rentable, generando una creciente concentración del capital (Furtado, 1971). Este proceso se exacerbó particularmente después de la segunda Guerra Mundial, con el impulso de las instituciones financieras internacionales creadas en el marco del acuerdo de Bretton Woods y el apoyo del Estado (Prado, 1957).

La influencia de las grandes empresas, por ende, no se puede analizar desde una perspectiva que reduzca su incidencia al plano económico, sino que debemos tener en cuenta su protagonismo en la toma de decisión en el ámbito nacional y en cuestiones de relaciones internacionales, sobre todo si se considera que una de las condiciones que permite la reproducción del capitalismo es la economía de guerra (Baran y Sweezy, 1974). A su vez, es esta dinámica la que permite y alimenta la perpetuación y reproducción de las relaciones centro-periferia, que en el caso de las multinacionales se materializa en las diferentes estrategias implementadas para lograr una permanente transferencia de excedentes. Estos grandes conglomerados (firmas que controlan múltiples actividades productivas no relacionadas) están compuestos por accionistas de diferentes países y extienden sus actividades a otros Estados -por ello son multinacionales- que además de la integración horizontal y vertical de las economías han logrado una mayor concentración de capital por medio del holding, que resulta de la fusión en grandes conglomerados, incrementando su influencia en las políticas nacionales e internacionales. De acuerdo con Prado (1957), devienen en Estados dentro del Esta$d o$, en tanto es éste el que legitima a estas compañías por medio de legislación y al devenir en principal consumidor.

Reflexionar sobre el rol del capital multinacional desde esta perspectiva nos lleva a la relación entre desarrollo, industria y capital. La vinculación entre estos conceptos, en América Latina, la abordó en buena medida la corriente estructuralista después de la segunda Guerra Mundial. Esta línea teórica surgió como una alternativa frente a los estudios que abordaban la posibilidad de desarrollo en países atrasados o subdesarrollados realizados desde una perspectiva neoclásica (las teorías del desarrollo) tendentes a resaltar los beneficios del comercio internacional y la necesidad de centrarse en las ventajas comparativas de cada 
país (Nahón et al., 2006: 333). El estructuralismo latinoamericano, impulsado básicamente por los miembros de la CEPAL, retomó algunas de las propuestas de las teorías del desarrollo, pero las combinó con posturas que cuestionaban parte de tales premisas.

De esta manera, las críticas keynesianas a la economía neoclásica se articularon con una suerte de perspectiva marxista schumpeteriana, atendiendo a que el sistema capitalista de libre empresa no era armónico y se desarrollaba con saltos y desequilibrios, dinámica que se asentaba en un sistema internacional organizado en centro-periferia, ciudad-campo, etc., postura que implicaba en última instancia la idea de explotación (Lusting, 1988: 36). También influyeron los postulados de Hirschman y Myrdal, quienes disentían con la posibilidad de crecimiento equilibrado en los países atrasados, además de asignar un rol fundamental al Estado en la planificación, la protección del mercado y la promoción de la industria (Myrdal, 1964). Es fundamental recordar que el estructuralismo retomaba buena parte de las aportaciones de Singer, quien -entre otras reflexiones en torno al desarrollo de las zonas atrasadas - afirmaba que la contribución de la inversión extranjera directa (IED) ${ }^{2}$ al desarrollo de los países deudores era escasa (Nurske, 1955: 36), pues tendía a alimentar el sistema de enclave orientado por las necesidades de los países desarrollados, conduciendo indirectamente a la producción primaria, desalentando de este modo el desarrollo dirigido a la industrialización (Kuntz, 2005: 148; Sen, 2005: 1029).

El pensamiento de la primera CEPAL, precisamente, se centraba en el rol fundamental de la industrialización, de manera específica en las posibilidades que abría la industria sustitutiva de importaciones (III). Este sistema se consideraba la vía más adecuada hacia el desarrollo en un contexto desfavorable para las economías latinoamericanas caracterizadas por la mano de obra desocupada, el desequilibrio externo y el deterioro de los términos de intercambio (Palma, 1987). El capital extranjero era uno de los factores fundamentales para el impulso inicial de la ISI. Con respecto a esto, se aclaraba que en una primera etapa de industrialización sería conveniente recibir capital extranjero oficial a fin de evitar los desequilibrios en la balanza de pagos que, en cambio, sí se podrían generar en caso de un ingreso desmedi-

\footnotetext{
${ }^{2}$ La inversión extranjera se puede dar por medio de exportación de productos realizados en la casa matriz, o instalando filiales en otros países. En general, el objetivo de este tipo de inversión es conseguir recursos, mercados, eficiencia y/o activos estratégicos más rentables que en sus países de origen (Fontoura, 2006: 64).
} 
do de capital extranjero privado (CEPAL, 1969: 138-139). La idea era pasar de una primera etapa sustitutiva destinada a la industria de bienes de consumo y de escaso valor agregado, a otra dedicada al desarrollo de la industria pesada, producción de maquinarias y bienes de capital (Teubal, 1973).

Fueron muchas las expectativas que se depositaron en esta propuesta, pero su puesta en práctica (que vale aclarar no siempre se llevó a cabo siguiendo las indicaciones de la CEPAL) no condujo a los resultados esperados, ya que generó limitaciones externas (desequilibrio en las balanzas de pagos) y contribuyó a desequilibrios sectoriales (Lusting, 1988: 43). De este modo, se fomentó una industria demasiado dependiente de la importación de insumos y bienes de capital ${ }^{3}$ que se articuló con el estancamiento del sector agroexportador que era, en definitiva, el que habilitaba las divisas para financiar la inversión extranjera (Ffrench-Davis et al., 2000). Otra consecuencia a largo plazo de este tipo de producción fue que permitió la excesiva protección de ciertas industrias, pues benefició en última instancia la propagación de filiales de empresas multinacionales (Furtado, 1971: 55) caracterizadas por la implementación de modelos tecnológicos intensivos en capital, contradictorios con el exceso de mano de obra disponible en los países latinoamericanos, población que al ser expulsada de la zona rural a la urbana y al quedar desocupada, terminó engrosando los sectores marginales urbanos (Tavares, 1998; Lusting, 1988: 45).

Ante estos resultados negativos de la puesta en práctica de la ISI (o "inesperados", como manifiesta Sunkel, 1998: 101) a fines de los cincuenta, la CEPAL propuso que se concretara un proyecto de integración económica que se venía analizando con funcionarios de los diferentes gobiernos latinoamericanos (especialmente los del Cono Sur) y que apuntaba a la conformación de un Mercado Común Latinoamericano (CEPAL, 1959). La propuesta finalmente cristalizó en el Tratado de Montevideo de 1960, mediante el cual se creó la Asociación Latinoamericana de Libre Comercio (ALALC). La idea de la CEPAL era que la integración entre los países de la región permitiría ampliar los mercados y complementar industrias, factor clave de atracción de capital, indispensable en los pasos

${ }^{3}$ Prado (1957) insistía en que este exceso de importaciones que generaba desequilibrios fuertes en la balanza de pagos, era inherente al sistema sustitutivo que de por sí inducía a una deformación de la economía. Desde la perspectiva de la CEPAL, en cambio, si bien se esperaba un aumento en las importaciones para el desarrollo de la industria, no se pensó que provocaría los efectos negativos que mostró en la práctica (CEPAL, 1959, 1969: 168). 
iniciales de la ISI (Ferrer, 1976). Asimismo, la integración se percibía como una posibilidad para conformar un bloque sólido frente a los países desarrollados, mejorando su postura en las negociaciones internacionales (Tamames y Huerta, 1999).

Si bien en un primer momento se consideró al capital extranjero como un aporte fundamental y absolutamente necesario, a partir de la experiencia de la IED en América Latina en los años cincuenta y sesenta determinada por el creciente impacto de las empresas multinacionales en la región, comenzó a instalarse la pregunta acerca de las posibilidades reales de desarrollo que podría generar este tipo de inversión en espacios periféricos (Prado, 1957; Furtado, 1971; Barnet y Müller, 1974; Caputo y Pizarro, 1975).

\subsection{Inversión extranjera directa en la ALALC: expectativas y consecuencias}

Si bien el capital extranjero se percibía como imprescindible para fomentar la industrialización en los ámbitos nacional y regional, desde un principio se planteó la necesidad de tomar previsiones. En este sentido, la Comisión Asesora de Asuntos Monetarios de la ALALC advirtió sobre la importancia de armonizar los tratamientos a la IED a fin de asegurar su contribución a la integración y al desarrollo. El establecimiento de pautas comunes era importante para evitar dos tendencias previsibles de la IED: que condujera al desarrollo de una competencia desleal para atraer inversiones en industrias de exportación, con la consiguiente localización antieconómica de las mismas, y que la IED generara una competencia entre las inversiones extranjeras en la zona y las industrias nacionales ya establecidas pero menos eficientes por diversas razones (Unión Panamericana, OEA, 1964: 522).

La armonización de normas con respecto al capital extranjero no se logró en el marco de la ALALC, por lo que el capital foráneo se rigió de acuerdo con las normativas de cada Estado. De manera muy sintética podemos decir que todos los países del bloque presentaban en sus legislaciones estímulos a la inversión nacional y extranjera, como la exoneración de gravámenes a la importación y del impuesto sobre la renta; la libertad de acceso al crédito de fomento y al crédito bancario comercial; la protección arancelaria industrial; la vigencia de regímenes cambiarios que controlaban el ingreso o egreso de divisas y establecían normas que limitaban las repatriaciones de capital, de sus utilidades 
y de otros pagos; ${ }^{4}$ el acceso a parques industriales o terrenos aportados por el Estado o con subsidio; los convenios de garantía (de resguardo de las inversiones) con Estados Unidos, cubriendo diversos riesgos (Nicolau, 1968: 21-22).

Esta tendencia a absorber capitales extranjeros coincidía con los objetivos de la ALALC y con las necesidades surgidas de la ISI. Sin embargo, esta aparente complementación entre IED y el desarrollo de las industrias nacionales y regionales en el marco de la ALALC demostró importantes tensiones en los hechos.

En lo relativo a la llegada efectiva de IED a la región, a fines de 1967 sumaba aproximadamente 14,000 millones de dólares, de los cuales 10,000 provenían de capitales norteamericanos, es decir, 71\% del total de la IED (Nicolau, 1968: 16-17). El capital norteamericano en aquel momento se hallaba en plena expansión si consideramos que entre 1946 y 1969 la IED estadounidense total (en el mundo) aumentó de 7,200 millones de dólares a 70,763 (Tugendhat, 1973: 42). En este aumento general de la IED estadounidense es importante tener en cuenta que la participación de la región latinoamericana era muy inferior en comparación con la inversión norteamericana que fluía hacia otras regiones (Nicolau, 1968: 17), por lo que si bien había un importante flujo de IED hacia América Latina, esta zona no era el principal destino de las inversiones, a pesar de la creciente rentabilidad de estas economías (Thorp, 2000: 58). Las ganancias de la economía norteamericana a partir de la IED en otras zonas, era en la mayoría de las ocasiones menor a las que obtenía en América Latina, sobre todo en lo relativo a sectores extractivos como la minería y el petróleo (cuadro 1).

Con respecto al destino de las inversiones, a lo largo de los años sesenta la IED predominó en el sector extractivo y en el manufacturero. La inversión en minería y petróleo se llevó a cabo en Venezuela, Perú, Chile y Colombia, mientras que la IED en industria manufacturera se instaló principalmente en México, Brasil y Argentina (cuadro 2). Con respecto a la primera, la actividad extractiva -si bien requería una importante inversión inicial- era probable ${ }^{5}$ que no llevara a nuevas actividades en el área

${ }^{4}$ Es importante aclarar que si bien las normativas nacionales respecto de la IED tendían a restringir el flujo de remesas, esta medida no resultó en mayor influencia en la llegada de inversiones, como lo muestra el caso de Brasil, que a pesar de medidas restrictivas fue uno de los países preferidos de la IED en América Latina (Nicolau, 1968).

${ }^{5}$ La realidad se encargó de confirmar esta presunción de Prado acerca de que era probable de que no se agregara valor al producto, en el caso de las inversiones en el sector extractivo. Un informe de la onU pone en evidencia que las inversiones estado- 


\section{Cuadro 1}

Estados Unidos: diferencia entre el aporte de capitales y la remesa de utilidades, 1960-1968 (millones de dólares)

\begin{tabular}{lrrrcr}
\hline & Total & Minería & Petróleo & Manufacturas & Diversas \\
\hline Todas las regiones & $-9,964$ & $-2,148$ & $-7,922$ & 949 & -806 \\
Canadá & -646 & 61 & 278 & -934 & -51 \\
América Latina & $-6,745$ & $-2,080$ & $-4,285$ & 376 & -757 \\
Europa & 4,796 & -59 & 3,165 & 1,399 & 291 \\
Otras & $-7,368$ & -107 & $-7,079$ & 108 & -289 \\
\hline
\end{tabular}

Fuente: ONU (1970).

\section{Cuadro 2}

\section{Destino de la inversión directa de Estados Unidos en los países de la ALALC (1968) (porcentajes)}

\begin{tabular}{|c|c|c|c|c|c|c|c|}
\hline & Minería & Petróleo & Manufacturas & $\begin{array}{l}\text { Servicios } \\
\text { públicos }\end{array}$ & Comercio & Otros & Total \\
\hline Argentina & $*$ & $*$ & 64 & $*$ & 5 & 31 & 100 \\
\hline Brasil & 5 & 6 & 69 & 2 & 13 & 5 & 100 \\
\hline Chile & 61 & $*$ & 7 & $*$ & 4 & 28 & 100 \\
\hline Colombia & 0 & 51 & 31 & 5 & 9 & 4 & 100 \\
\hline México & 8 & 3 & 68 & 2 & 12 & 7 & 100 \\
\hline Perú & 61 & 6 & 14 & 3 & 7 & 9 & 100 \\
\hline Venezuela & $*$ & 68 & 14 & 1 & 10 & 7 & 100 \\
\hline Otros países & 8 & 42 & 13 & 11 & 8 & 18 & 100 \\
\hline
\end{tabular}

* Incluido en otros sectores.

Fuente: ONU (1970).

(Prado, 1957). Por otra parte, se trata de recursos naturales que se agotan con el consiguiente costo para la región de la cual se obtuvieron.

En cuanto a la manufactura, los que recibieron este tipo de inversión fueron aquellos países de la ALALC con mercados más desarrollados. De esta manera, a principios de 1970 la IED norteamericana en ese sector alcanzaba 752 millones de dólares en

unidenses en el sector extractivo en Europa, en cambio, sí apuntaban a agregar valor al producto: "En 1957, en América Latina, el 74\% de la inversión en el sector estaba relacionada directamente con la extracción. En Canadá ese porcentaje era de $44 \%$ y en Europa, de sólo 9\%. En el caso de Europa un 72\% de la inversión estaba orientada a refinería y distribución, el resto a transporte. En América Latina, el 26\% estaba en refinación y distribución. Es decir, el sector del petróleo en Europa está conceptualmente muy próximo al sector manufacturero" (1970: 306). 
México, 722 en Brasil y 617 en Argentina (Furtado, 1971: 55). Debemos aclarar que la IED estadounidense mantenía una fuerte tendencia al oligopolio. Solamente en el sector manufacturero eran 143 empresas las que controlaban $41 \%$ de las inversiones totales en industria manufacturera (Furtado, 1971: 33). Aunque en un primer momento este tipo de inversión generó buenas expectativas, con el tiempo demostró que era perjudicial pues, por un lado, las empresas transnacionales se instalaron en los mercados más desarrollados generando un fuerte desequilibrio regional, y por otro, implicó una importante competencia con las industrias locales menos desarrolladas (Grunwald et al., 1973: 138). Es claro que no fue sólo la ALALC quien amparó la penetración de las subsidiarias de empresas internacionales que terminaron por dominar los sectores económicos más dinámicos, sino que este fenómeno fue impulsado en algún punto por la dinámica de la IsI (Ferrer, 1976).

Ahora apuntamos algunos de los mecanismos que aumentaban la rentabilidad de la mayoría de las empresas que invertían en la región, a pesar del paulatino deterioro de las economías de la ALALC. Un aspecto fundamental es el relativo a la cantidad de remesas por utilidades enviadas al país de origen de la inversión (en el caso latinoamericano, la mayoría eran remitidas a Estados Unidos). La misma CEPAL reconocía esta limitación de la IED por lo cual advertía que, a fin de que este tipo de inversión contribuyera al desarrollo, el ingreso de capital total debía superar los gastos por servicio de inversiones extranjeras. No obstante, a fines de los sesenta era evidente el desequilibro generado por este tipo de inversión, ya que los montos de IED solían ser menores que las remesas totales de utilidades (CEPAL, 1969: 157-161). En ese mismo periodo, Furtado (1971) sostenía que si el sector moderno en expansión lo controlaban firmas extranjeras, era de esperar que se generaran problemas en la balanza de pagos y de desnacionalización de la economía. Varios años antes, Prado (1957) aseguraba que era difícil controlar el capital monopólico instalado en países subdesarrollados, porque no había restricciones que lograran frenar el desequilibrio generado por las remesas hacia el exterior de las ganancias obtenidas por tales ventas. Una consecuencia directa de esta característica de la IED fue la tendencia a conformar islas de producción, por lo que importantes áreas geográficas quedaban relegadas (Katz, 2006: 45).

Otra estrategia muy frecuente consistía en que las compañías multinacionales absorbían aquellas empresas locales que habían adquirido cierto grado de competitividad (Barnet y Müller, 1974: 
144). ${ }^{6}$ Este fenómeno es el que permitió a las empresas multinacionales crecer aun en economías con serias limitaciones. Justamente, la expansión de las empresas norteamericanas se realizó en gran parte por medio de la adquisición de instalaciones ya existentes en los países latinoamericanos, cuando estas economías pasaban por un periodo de crisis (Furtado, 1971: 56). Es interesante agregar que los acuerdos de complementación industrial especialmente impulsados por la ALALC, en general fueron aprovechados por las multinacionales (Ffrench-Davis et al., 2000: 130-131), que al adquirir las empresas locales accedían a las rebajas arancelarias y otros beneficios de promoción industrial de la ALALC.

A esto se sumaban dos estrategias fundamentales: los precios de transferencia y la conformación de plataformas de exportación (Barnet y Müller, 1974). Los precios de transferencia implicaban fijar precios intracompañía, entre filiales, a fin de maximizar la ganancia global de las matrices. Esto generaba un doble proceso de integración, mediante el cual la empresa se integraba a sí misma entre sus filiales (tengamos en cuenta la diversificación de las grandes empresas, en múltiples y diversas actividades), al tiempo que se generaba una integración de la región de inversión (América Latina) a la economía originaria de dicho capital (la estadounidense) (Furtado, 1971). ${ }^{7}$ Así, este doble proceso de integración obstaculizaba simultáneamente la integración económica en el ámbito latinoamericano. Las plataformas de exportación estaban constituidas por los sectores y empresas dedicadas a la producción de bienes destinados a satisfacer las demandas del mercado interno norteamericano, pero que al recurrir a recursos y mano de obra más barata, ${ }^{8}$ producía a menor costo que en Estados Unidos (Barnet y Müller, 1974: 134).

${ }^{6}$ Un ejemplo clave es el de la IED en Argentina en la década de los sesenta, periodo en el cual los sectores siderúrgico y automotriz pasaron a manos de grandes empresas extranjeras. Entre las 10 empresas más grandes de América Latina se encontraban Siam Di Tella en el primer lugar y la Kaisser Argentina en el quinto. En 1967 se transfirieron a capital internacional, específicamente a empresas norteamericanas, hegemónicas en siderurgia, industria automotriz, cigarrillos, e incluso, en sectores menos tradicionales como el del azúcar, la ganadería, los alimentos, los textiles, etcétera (García Lupo, 1971: 52).

7 Tavares (1998) también aclara que las multinacionales no sufrían la escasa integración de los sectores productivos en el ámbito nacional, porque su meta era la integración con las casas matrices.

${ }^{8}$ La fuerza de trabajo fue un aspecto especialmente estudiado por la CEPAL, llegando a la conclusión de que una de las grandes diferencias entre los países periféricos y los centrales era el grado de organización de la mano de obra en estos últimos, a diferencia del excedente de fuerza de trabajo y la falta de organización en los países periféricos (Kerner, 2003; CEPAL, 1969). 
Las estrategias que implementó el capital multinacional para asegurar su rentabilidad y expansión en la periferia ${ }^{9}$ tenían sus bases en el carácter monopólico y oligopólico del capitalismo de posguerra, que consistía en determinar el consumo a partir de la producción, lo cual llevaba en última instancia a definir estilos de vida (Prado, 1957). Este fenómeno guarda una estrecha relación con las advertencias acerca del costo económico y social que implicaba el efecto demostración en economías subdesarrolladas, porque fomentaba el consumo de bienes de lujo en sectores minoritarios, pero sostenido por el conjunto de la economía (Pinto, 2000).

Las consecuencias de la IED en las economías de la ALALC dejan entrever las debilidades de las expectativas de las premisas estructuralistas respecto del capital extranjero. En este sentido, es claro que los objetivos del capital extranjero, y en especial del multinacional, eran diferentes e incluso contradictorios con la idea de complementación, desarrollo autónomo y equilibrado tanto en el ámbito nacional como regional (Kerner, 2003). Por otro lado, desde una perspectiva neoestructural se postula que hubo cierta ingenuidad en la confianza de la CEPAL con respecto a los préstamos extranjeros (incluido el capital oficial definido como deseable) en tanto se pensaba que serían accesibles (Thorp, 2000). No obstante, podemos decir que esa excesiva confianza en el capital extranjero no fue casual, pues se presentó como consecuencia de las secuelas de la economía neoclásica presentes en el pensamiento de la CEPAL, como lo confirmaron algunos análisis críticos. ${ }^{10}$

\subsection{Consideraciones sobre el rol del capital multinacional en} América Latina a partir de la experiencia de la década de los sesenta

Las falencias del pensamiento estructuralista las detectó y analizó la CEPAL misma, lo cual se puede percibir en ciertas reflexiones de Prebisch (1962), a la vez que algunos intelectuales que se habían formado en dicha institución se orientaron hacia una línea bastante crítica con respecto a los postulados estructuralistas,

\footnotetext{
${ }^{9}$ La expansión del capital hacia la periferia como válvula de escape que hace posible la reproducción del sistema capitalista, es una de las tesis de la perspectiva imperialista y fue desarrollada por Lenin y Luxemburgo a principios del siglo xx. Luego de la segunda Guerra Mundial la retomaron los dependentistas, marxistas y neomarxistas.

${ }^{10}$ Una de las críticas más sólidas con respecto a la postura de la CEPAL en lo relativo al capital extranjero es la de Caputo y Pizarro (1975).
} 
como Furtado (1971) y, en cierta medida, Sunkel y Paz (1980). Buena parte de las discusiones se centraban en lo relativo a la ISI y al rol del capital multinacional, que dieron muestra de que no correspondían con las metas del desarrollo. Desde esta perspectiva, la inversión extranjera no era simplemente la propiedad de los activos existentes en el país por parte de personas físicas o jurídicas extranjeras, sino que implicaba la inserción en el sistema nacional de decisiones de grupos que formaban parte de otras economías nacionales. El problema era entonces tanto más importante, debido a que las empresas extranjeras, en su mayoría de grandes dimensiones, ejercían el control de los sectores en los que operaban y ocupaban gran parte de ramas de actividades en que es más rápido el progreso. En este sentido, el desarrollo era menos una cuestión de inversiones que de creación de un sistema económico articulado y capacitado para autodirigirse (Furtado, 1971: 59).

A su vez, a mediados de los sesenta se gestó una línea de reflexiones que radicalizaron los postulados cepalinos: la escuela de la dependencia (Blomström y Hettne, 1990; Beigel, 2006). En general se plantean las distinciones entre estas corrientes (Lusting, 1988; Kay, 1998; Love, 2005), pero aquí nos interesa atender las continuidades presentes entre ambas (Beigel, 2006) centrándonos en el rol del capital multinacional en el desarrollo de América Latina como espacio periférico. Es precisamente en la conceptualización centro-periferia y sus implicaciones donde hallamos uno de los ejes articuladores entre estructuralismo y escuela de la dependencia, que resulta asimismo fundamental en lo relativo al rol del capital multinacional en economías periféricas.

La escuela de la dependencia tomó esta temática como aspecto central de sus estudios, mediante el rescate de parte de las ideas estructuralistas y también recurriendo a la teoría del imperialismo y al neomarxismo, como los trabajos de Paul Baran, Paul Sweezy y Harry Magdoff, entre otros (Dos Santos, 2002). Si bien los intelectuales que integraban esta escuela diferían en algunas cuestiones (motivo por el cual se agrupan en una escuela y no en una teoría de la dependencia), podemos decir que en general suponían que los obstáculos fundamentales para el desarrollo se hallaban en la división internacional del trabajo, es decir, estaban fuera de la economía subdesarrollada. Esta división internacional del trabajo se analizaba con base en relaciones entre regiones, donde eran primordiales el centro y la periferia, porque esta última transfería su excedente a la primera. En el entendido 
de que la periferia no podía apropiarse de su excedente, el desarrollo en el centro implicaba el subdesarrollo de la periferia, siendo ambos parte de un mismo proceso global. Al ser imposible el desarrollo en la periferia del sistema capitalista, la única forma de alcanzar el desarrollo era por medio de una ruptura más o menos revolucionaria con el sistema, a fin de eliminar los obstáculos externos (Blomström y Hettne, 1990: 104).

En lo relativo específicamente al capital multinacional, se sostenía que no era un motor de desarrollo, sino todo lo contrario. El imperialismo se consideraba el eje del sistema internacional y ello implicaba no solamente dominación económica sino determinadas relaciones de poder. En el centro de tales relaciones de poder dentro del sistema internacional, se hallaba la corporación multinacional. El objetivo de la inversión extranjera era entonces, en general, "expandir sus mercados, garantizar las fuentes de materias primas, el logro de máximos beneficios y el establecimiento de posiciones monopólicas" (Johnson, 1970: 113114). Los dependentistas señalaban como un aspecto fundamental del imperialismo la relación entre el capital monopólico y el complejo industrial-militar norteamericano, sobre los cuales se basaba el desarrollo del capitalismo de la posguerra, entendiendo que el capital monopolista era inherente al capitalismo en su etapa neocolonial (Baran y Sweezy, 1974).

En esta línea (articulando las perspectivas del imperialismo, el neomarxismo y la dependencia), Caputo y Pizarro (1975) hacen una sólida crítica a la CEPAL, específicamente en lo relativo al capital extranjero. La deficiencia en la aproximación de la CEPAL residía en su atadura a las premisas neoclásicas respecto del rol fundamental del capital para la industrialización latinoamericana, ${ }^{11}$ aspecto que refutan los autores, en tanto este capital no sólo no contribuía al desarrollo de la región, sino que era una fuente de permanente extracción de excedentes (Caputo y Pizarro, 1975: 130). Esta aportación es fundamental para relativizar el alcance crítico del estructuralismo, lo cual contribuye a comprender la naturalidad con que se llevó a cabo el giro hacia le neoestructuralismo (aspecto que abordaremos en el siguiente apartado).

${ }^{11}$ Tales postulados son: “1) El capital extranjero otorga recursos adicionales de divisas que permiten paliar el desequilibrio implícito existente entre las importaciones y exportaciones; 2) El capital extranjero constituye un complemento del ahorro nacional en su aspecto más vital, en cuanto, precisamente otorga divisas para importar bienes de capital y materias primas imprescindibles para el proceso de industrialización; 3) El capital extranjero en inversión directa en nuestros países es una forma importante de transferencia de adelanto tecnológico, modelos de organización, publicidad, etcétera” (Caputo y Pizarro, 1975: 47). 
De acuerdo con lo revisado hasta aquí, observamos que el estructuralismo se centraba en el desarrollo nacional, en contraposición con la visión más global de los dependentistas, que concebía al Estado nacional colonizado por una burguesía que impulsaba políticas de subdesarrollo, fortaleciendo los lazos de dependencia (Gunder, 1970: 45).

Ahora bien, una de las falencias del estructuralismo, e incluso de la escuela de la dependencia, es que no indagaron demasiado en las múltiples dimensiones y actores implicados en las relaciones entre Estados, teniendo en cuenta que la ALALC proponía la integración entre Estados. ${ }^{12}$ La tendencia fue a naturalizar al Estado como promotor del proceso hacia el desarrollo, sin cuestionar demasiado quiénes eran el Estado, qué grupos tenían mayor incidencia en el delineamiento de políticas, qué grupos ocupaban la esfera política formal, etcétera. ${ }^{13}$

La CEPAL supuso desde un principio que la iniciativa de la integración sería apoyada por la clase política y por el sector empresarial de los países de la ALALC. No obstante, al cabo de una década de puesta en práctica de la ALALC se sostenía que uno de los factores que limitaba este proceso era la falta de voluntad politi$c a$, ya que junto con los instrumentos jurídicos e institucionales, ésta constituía por definición uno de los componentes esenciales de cualquier intento de integración (Herrera, 1970: 311). También el sector empresarial e industrial local mantenía una postura poco sólida con respecto a la integración regional, como lo sugiere Teubal:

En primer lugar, estos industrialistas y empresarios aparecieron hace muy poco [se refiere a las burguesías nacionales de la región]. En algunos de los países latinoamericanos constituyen una clase sin mucha fuerza política y sin una ideología propia, clara, según la cual actuar. En segundo término, resulta difícil reconciliar sus intereses con los de la burguesía nacional de otros países, de modo que es dificultoso imaginar su aceptación de una serie de reglas del juego, aplicables a la región en conjunto. Y por último, parecería que la burguesía nacional, en lugar de oponerse con energía a los intereses más tradicionales extra-

${ }^{12}$ Esta debilidad es más reprochable al estructuralismo que a la dependencia, porque fue la primera corriente que impulsó el proceso de integración regional bajo la guía de la CEPAL y la que concebía la integración como motor de desarrollo.

${ }^{13}$ Se puede argumentar que al ser un organismo creado para el análisis económico, la CEPAL no tenía la necesidad ni la obligación de abordar de modo profundo los aspectos políticos de las sociedades de América Latina. No obstante, la CEPAL también se creó con el objetivo de brindar asesoramiento a los gobiernos de la región y esa tarea en sí misma implica la participación en la vida política, tarea que por cierto sigue realizando. 
rregionales, se mostraría probablemente dispuesta a colaborar con ellos (1973: 130).

Este tipo de apreciación da cuenta de las expectativas depositadas en este sector con respecto al proceso de integración, y la importancia que cobró de hecho en tal proceso.

A pesar de ello, no se tuvieron en cuenta las prácticas de los sectores y grupos que influenciaron de modo directo o indirecto la toma de decisión en el ámbito estatal (y en las relaciones entre Estados), lo cual implicaba abordar el terreno de lo político y su vinculación con lo económico y lo militar (que era crucial en aquel periodo). Tampoco se especificaron los diversos intereses que se hallaban mejor representados que otros en la puesta en práctica de la ALALC. Se otorgó, entonces, escasa importancia al grupo de empresarios, industriales y funcionarios encargados de llevar a cabo este proceso que -aun cuando no se mostraban opuestos necesariamente a las políticas estatales que promovían la ISI- más que defender los intereses nacionales, persiguieron sus propios intereses (individuales o de grupo), por ejemplo, al percibir como una oportunidad la asociación con el capital multinacional.

La suposición de que existe una relación directa entre los intereses de los empresarios e industriales y los intereses nacionales, se basa en la presunción de que existe una burguesía nacional dispuesta a llevar a cabo el proceso de industrialización y desarrollo. Esta suposición no profundiza en la articulación entre la burguesía y el Estado, es decir, entre los intereses privados y el interés público que resulta crucial si estamos de acuerdo en que el poder burgués hizo de la iniciativa privada y de su sistema un verdadero bastión que protege y une los intereses privados internos y externos, que se relacionan con el poder público también en el plano de lo económico (Fernández, 2008: 257). Con respecto al resultado del proceso de integración, Prado sostiene que el problema consistía en la verdad, "aunque no siempre se confesara", en asegurar la supervivencia de una "industria improvisada” (1968: 231) que atendía la demanda de capas reducidas de la población con mejor poder adquisitivo y que se encontraban privadas de sus importaciones habituales.

Por último, es necesario aclarar que si bien los dependentistas se mostraban escépticos con respecto a las posibilidades que ofrecía la alternativa de la integración regional, aceptaban que constituía en cierta medida uno de los caminos para disminuir los lazos de dependencia con las potencias centrales, siempre y cuan- 
do se implementaran modificaciones importantes en la puesta en práctica de la ALALC ("Declaración de los economistas latinoamericanos", junio 1965, en Gunder et al., 1970: 373).

Más allá de las coincidencias y desacuerdos entre estructuralistas y dependentistas, el resultado de la proliferación de capital extranjero multinacional no favoreció el desarrollo de la ALALC. Esto se reflejó en la conformación del Pacto Andino a fines de los sesenta, firmado por Colombia, Bolivia, Chile, Ecuador y Perú y se constituyó como un acuerdo subregional en el marco de la ALALC, planteando como una de sus metas fundamentales la regulación del capital extranjero (Waldman, 1983). ${ }^{14}$

\section{La integración del Cono Sur hoy: el Mercosur y el capital multinacional}

\section{La apertura de los países latinoamericanos al capital extranjero} creció durante la década de los sesenta y se intensificó en los setenta (Ffrench-Davis et al., 2000). Esto coincidió con la crisis energética de los Estados centrales y en el contexto de la decadencia del patrón dólar (Tamames, 1990). La afluencia de capitales extranjeros fue paralela, asimismo, a la reinstauración en la academia de los principios neoclásicos ${ }^{15}$ y las premisas moneta-

${ }^{14} \mathrm{Si}$ nos remitimos al cuerpo normativo que dio origen al Pacto Andino (26 de mayo 1969), observamos que en el Capítulo III, en los Artículos 27 y 28 se aclara: "Antes del 31 de diciembre de 1970 la Comisión, a propuesta de la Junta, aprobará y someterá a la consideración de los Países Miembros un régimen común sobre tratamiento a los capitales extranjeros y entre otros, sobre marcas, patentes, licencias y regalías. Los Países Miembros se comprometen a adoptar las providencias que fueren necesarias para poner en práctica este régimen dentro de los seis meses siguientes a su aprobación por la Comisión. Artículo 28: Antes del 31 de diciembre de 1971 la Comisión, a propuesta de la Junta, aprobará y propondrá a los Países Miembros el régimen uniforme al que deberán sujetarse las empresas multinacionales".

${ }^{15}$ El núcleo de la economía neoclásica lo constituyen el libre comercio y las ventajas comparativas. Con respecto al primero, Caputo y Pizarro exponen: "La teoría del comercio internacional plantea que existe una lógica interna del sistema de relaciones internacionales que lleva necesariamente al equilibrio, y se considera que cualquier situación de desequilibrio es disfuncional para la estructura misma de dicho sistema; tal desequilibrio se corregirá automáticamente, gracias a los desplazamientos internos que se producirán en ese sistema [...] en íntima relación con el factor anterior, la teoría del comercio internacional entiende las relaciones económicas entre los países sobre la base de la libre competencia de éstos en el mercado internacional. Esto significa que los precios de los productos que entran en el mercado mundial sólo son definidos por la fuerza de las leyes de oferta y demanda que rigen en dicho mercado" (1975: 14-15). En lo relativo a ventajas comparativas, la economía ortodoxa sostiene que: "El principio de las ventajas comparativas es fundamentalmente una idea del sentido común e importante para toda economía; cada individuo, o cada comunidad, o cada país, deben especializarse en la producción de aquellos bienes respecto de los cuales son relativamente más eficientes" (Kindleberger, 1960, en Caputo y Pizarro, 1975: 15). 
ristas impulsadas fuertemente en los ochenta y consagradas en los noventa (Kuntz Ficker, 2005).

A partir del creciente endeudamiento, los países latinoamericanos otorgaron otra vez un rol fundamental a la producción primaria porque necesitaban desesperadamente las divisas para enfrentar el grave desequilibrio externo y sus repercusiones en el ámbito interno. En este marco, el comercio entre los países de la región se constituyó en una de las alternativas deseables (Rofman, 1993; Schvarzer, 2001). A partir del acuerdo entre los presidentes Alfonsín y Sarney (Programa de Integración y Cooperación Económica entre Argentina y Brasil, PICAB, julio 1986), estos dos países se comprometieron a llevar a cabo una estrategia comercial conjunta, planteando como eje no sólo la liberalización comercial, sino la posibilidad de promover el desarrollo industrial, especialmente en sectores de mayor desarrollo tecnológico, como aviación y petroquímica (Schvarzer, 2001: 24). ${ }^{16}$

Mas allá de estas iniciativas, con el paso de los años y la profundización de la crisis, creció el protagonismo del ajuste estructural que condujo a la progresiva (y en la mayoría de los casos indiscriminada) liberalización de los mercados. En este contexto, el proyecto de integración se inclinó hacia políticas y acciones centradas en el mercado y la competencia, dejando de lado el objetivo de desarrollo en términos estructuralistas. De acuerdo con tales lineamientos, se abandonaron los proyectos de industrialización y los avances en sectores de tecnologías más complejas.

La firma del Tratado de Asunción en 1991 dio origen al Mercado Común del Sur (Mercosur), integrado por Brasil, Argentina, Paraguay y Uruguay. No obstante este paso adelante, ${ }^{17}$ los grandes del Mercosur se volcaron en decisiones y políticas unilaterales. El gobierno argentino de los noventa decidió implementar las recetas neoliberales de privatización y desregulación sin ningún tipo de proyección respecto del costo que esto podía te-

\footnotetext{
${ }^{16}$ Esta idea de focalizar en el desarrollo tecnológico descansaba en parte en el éxito de los países asiáticos, que mostraron un impresionante despegue económico, con base en una economía centrada en la exportación y en la especialización en sectores de alta tecnología. Este fenómeno sirvió de excusa para implementar las medidas neoliberales del Banco Mundial, a la vez que inspiró algunos de los postulados fuertes del neoestructuralismo (Kay, 1998).

${ }^{17}$ En realidad, desde perspectivas como la de Rofman (1993), las primeras negociaciones entre Brasil y Argentina (anteriores al Tratado de Asunción) implicaban de por sî un modelo abierto a la discusión, mientras que el Mercosur se caracterizó por pautas rígidas, por ejemplo, la reducción lineal y automática de los aranceles, agudizando las tensiones de las empresas menos desarrolladas para competir con empresas del país vecino.
} 
ner en los ámbitos económico, político y social. El gobierno de Brasil, por su parte, si bien se orientó a medidas de corte neoliberal, mantuvo bajo la protección del Estado algunas actividades e industrias dirigidas, incluso de sectores clave para el desarrollo tecnológico (petróleo, petroquímica, etc.) (Ferrer, 1998; Schvarzer, 2001).

Al igual que la ALALC, uno de los objetivos que impulsó al Mercosur fue lograr un mercado de mayores dimensiones como factor de atracción de capital extranjero. A su vez, se pensaba que la conformación de un bloque sería una vía para favorecer la ubicación de los productos de estos países en el mercado internacional. Otra continuidad con lo sucedido en los sesenta es la persistencia de asimetrías, sólo que en la actualidad parecen ser aún mas acentuadas tanto entre Brasil y Argentina como entre éstos y las economías más pequeñas de Uruguay y Paraguay (Katz, 2006). ${ }^{18}$ Tales brechas resultan cruciales, en particular, en lo relativo a la IED.

La lógica de las multinacionales no se ha modificado en relación con la dinámica seguida en los años sesenta, más bien se han profundizado sus estrategias para maximizar ganancias. Persisten en la búsqueda de recursos y mano de obra más barata que en los países de origen, aprovechan la cercanía de los mercados y la transferencia de remesas por utilidades. No obstante, se puede percibir un cambio del lado de los países anfitriones de las filiales de compañías transnacionales, para permanecer dentro del sistema en tanto cada vez necesitan con mayor urgencia el capital del que disponen tales empresas. De esta manera, los gobiernos ofrecen más y mejores ventajas para atraer la inversión de capitales extranjeros, no sólo en América Latina, pues esta competencia por atracción de capital se da a lo largo y ancho del Tercer Mundo, siendo China, India y el sudeste asiático las áreas de mayor éxito en esta tarea. Por otra parte, la lógica de acumulación del gran conglomerado de posguerra se ha exacerbado, materializándose en la constitución de holdings que abarcan desde la producción de materias primas hasta la prestación de servicios.

${ }^{18}$ Con respecto a la brecha Brasil-Argentina, en los años veinte la economía argentina era el doble que la brasileña. En 1937-1938, el PIB argentino era 50\% más grande que el de Brasil. En 1960, las economías de ambos países se habían equiparado. En la actualidad, sin embargo, la diferencia entre los dos países es muy significativa. En 1965, el PIB brasileño era $25 \%$ mayor que el argentino, y en 2003 ya superaba en cuatro veces al de su vecino (Sevares, en Katz, 2006: 40). 


\subsection{La inversión extranjera directa en el Mercosur y el planteamiento neoestructuralista}

En el marco de la normativa particular del Mercosur existen dos protocolos o tratados que se refieren a la inversión de capital que no están vigentes: el Protocolo de Colonia (enero 1994) y el Protocolo de Buenos Aires (agosto 1994). Estos acuerdos, sobre todo el primero, se adecuan a las pautas para la inversión del GATS/OMC de la Ronda de Uruguay (1986-1994), a pesar de que son normativas que no fueron diseñadas estrictamente para un proceso de integración regional, por lo que pueden ser poco pertinentes e incluso perjudiciales para el desarrollo del Mercosur (Torrent, 2006).

$\mathrm{Al}$ no haber un marco regulatorio regional vigente respecto de la IED, los principales acuerdos de protección y promoción extranjera terminan por ser los APRI (Acuerdos de Promoción y Protección de Inversiones), especialmente en forma de tratados bilaterales (BIT, bilateral trade agreements) que dependen de cada país y que coinciden con las normativas del TLCAN (Tratado de Libre Comercio de América del Norte) (Torrent, 2006). En el ámbito multilateral el tratamiento de las inversiones es bastante limitado, basado en algunas normativas del FMI sobre circulación de capitales en las intermediaciones de organismos de solución de controversias, como el CIADI (Centro Internacional para el Arreglo de Disputas por Inversiones, creado por el Banco Mundial en 1965) y el MIGA (Acuerdo Multilateral de Garantía a las Inversiones) como agencia de seguro de las inversiones frente a riesgos políticos (Fontoura, 2006). Los APRI, no obstante su continua implementación, contienen importantes aspectos negativos, como la asimetría implícita en sus normas (que en general parece estar a favor de los inversores, dejando de lado las demandas de los trabajadores y las condiciones ambientales) y la tendencia a apoyar a los acreedores, que usualmente son países desarrollados, en detrimento de la condición de los deudores, que suelen ser países periféricos (Fontoura, 2006: 69-70).

Con respecto a los flujos de IED hacia América Latina durante el año 2006, se puede decir que aumentaron (aunque en un mínimo porcentaje) respecto de $2005,{ }^{19}$ alcanzando los 72,440 millones de dólares, de los cuales 44,679 millones se destinaron a

${ }^{19}$ La estabilidad de la IED hacia América Latina contrasta con el aumento de la IED que fluyó hacia otras zonas en desarrollo, como los países asiáticos. 
América del Sur. ${ }^{20}$ Argentina recibió 4,809 millones de dólares, Brasil 18,782, Uruguay 1,374 y Paraguay 117 millones de dólares. Los países de origen de la inversión fueron, en general, Estados Unidos y algunos de la Unión Europea, sobre todo el Reino Unido, Francia y España (CEPAL, 2007). Se puede observar la fuerte brecha no sólo entre las economías más pequeñas del Mercosur (Uruguay y Paraguay) y las más grandes (Argentina y Brasil), sino también la dimensión que ha alcanzado la IED en Brasil, en comparación con Argentina.

No obstante estas diferencias en inversiones, es probable que el punto fuerte del Mercosur se encuentre en el comercio, que resultó ser el eje de la integración de hecho (Torrent, 2006). Si bien es claro el aumento del intercambio en el ámbito regional, desde algunas perspectivas se relativiza este avance, debido a que se debe en parte a un desvío comercial. Este efecto contradice el ideal del regionalismo abierto sostenido como meta deseable y necesaria (CEPAL, 1990; Fuentes, 1994; Ocampo, 1998).

En el ámbito regional, los alcances y limitaciones del proceso de integración actual no se conciben de manera unánime debido a las diferentes perspectivas sobre el tema. Sin embargo, consideramos que la mayoría de las lecturas acerca de este proceso, desde principios de la década de los noventa, se han realizado desde la óptica del neoestructuralismo, corriente que retoma aspectos medulares del estructuralismo, combinados con algunos aportes del neoliberalismo (Kay, 1998).

Un concepto que articuló la transición entre el estructuralismo y el neoestructuralismo es el de desarrollo dependiente asociado, creado por Cardoso y Faletto (1973). Esta noción implica que aún en condiciones de dependencia se puede llevar a cabo un proceso de desarrollo. Lo que se oculta detrás de esta afirmación es una aceptación de las condiciones de dependencia en tanto no constituyen un impedimento total para el desarrollo, con lo cual, lo que debe hacer una economía nacional es aprovechar del mejor modo posible la condición de dependiente y asociada. ${ }^{21} \mathrm{El}$

${ }^{20}$ La IED en América del Sur se dirige especialmente al sector de recursos naturales (CEPAL, 2007). Esta característica podría identificarse con un tipo de inversión extractiva que requiere mucho capital inicial, pero escasa atracción de otras inversiones. Otro dato provisto por la CEPAL (2007) es que la IED en el área de México y el Caribe busca eficiencia, especialmente para exportar al mercado estadounidense, lo cual se asemeja a las características de plataforma de exportación; a su vez, ninguna de estas inversiones se orienta a la búsqueda de activos tecnológicos.

${ }^{21}$ Esta idea se vincula con una de las variantes del realismo en relaciones internacionales, elaborada también en el contexto latinoamericano de la década perdida e inicios de los noventa, denominada realismo periférico. Éste, siguiendo la conceptualización 
neoestructuralismo se basa en esta aceptación de la condición dependiente y periférica de las economías de América Latina, y supone que es posible alcanzar un mayor nivel de desarrollo acomodándose a las reglas del mercado internacional.

La CEPAL ha sido una de las instituciones clave para impulsar esta perspectiva. En un documento de dicha institución, presentado en 1990, se planteaba la concepción de transformación productiva con equidad ${ }^{22}$ como eje del desarrollo en la región y se sostenía que el desafío de los noventa, entre otras cuestiones, era fortalecer la democracia a la vez que se debían ajustar y estabilizar las economías, incorporarlas a un cambio tecnológico mundial intensificado, modernizar los sectores públicos, elevar el ahorro, mejorar la distribución del ingreso, etc. Asimismo, en esta nueva dinámica entre el sector privado y el Estado, se proponía como principio la selectividad de las acciones del Estado, la autolimitación de éstas, la simplificación y la descentralización de las inversiones estatales. Los avances se concebían como posibles en un marco de cooperación regional e internacional, en el cual se ganaría legitimidad, credibilidad y eficacia mediante la transformación productiva para exigir que los países industrializados asumieran su propia responsabilidad en el ordenamiento de la economía mundial (CEPAL, 1990). En síntesis, “en el decenio de 1990, la CEPAL actualizó su pensamiento para adecuarlo a la nueva realidad de apertura comercial, movilidad internacional de capitales, privatización y desregulación” (Bielschowsky, 2009: 176)

Los objetivos de integración regional, a su vez, se adecuaron a esta concepción de transformación productiva con equidad, planteando la necesidad de un regionalismo abierto que implicaba (e implica) la cooperación regional por medio de la disminución de barreras al comercio y a la inversión, sin descartar acuerdos con terceros. La meta principal consistía en continuar con los esfuerzos iniciados en décadas anteriores para lograr la mejor inserción posible de las economías latinoamericanas al mercado internacional "como respuesta a la creciente globalización de la economía y

de Carlos Escudé, implica que los países periféricos deben aceptar sus condicionamientos y limitaciones en cuanto a espacios periféricos, aprovechando lo mejor posible sus ventajas y subordinándose a los Estados más poderosos (Colacrai, 1992).

${ }^{22}$ Esta nueva propuesta, elaborada por Fernando Fajnzylber, se planteó como una alternativa frente al "contexto de los ajustes recesivos practicados en gran parte de los países de la región. Ello condujo a reducir la importancia relativa de los dos temas hasta entonces principales - desarrollo productivo e igualdad-y a reorientar las prioridades a un campo en que la institución no había intervenido mayormente en los decenios anteriores, a saber, el análisis de la estabilidad macroeconómica y sobre todo de la trilogía deuda-inflación-ajuste” (Bielschowsky, 2009: 176) 
a las insuficiencias demostradas en numerosos casos por la anterior estrategia de industrialización" (CEPAL, 1994, Síntesis y conclusiones 10.a). Una de las condiciones para lograr esa inserción era aumentar la competitividad de las economías en un mundo donde tanto las economías desarrolladas como los países "en vías de desarrollo" tenían la finalidad de instaurar una "economía internacional más abierta y transparente", en la cual la integración se percibía como la encargada de fortalecer "los cimientos de una economía internacional libre de proteccionismo y de trabas al intercambio de bienes y servicios" (CEPAL, 1994, Síntesis y conclusiones 12 , las cursivas son nuestras).

Hacia finales de la década, en ocasión del cincuenta aniversario de la CEPAL, el entonces secretario ejecutivo de la institución, José A. Ocampo, ratificaba el planteamiento de la transformación productiva con equidad como núcleo del desarrollo y mencionaba algunas características esenciales de dicha propuesta, como "la valoración de una macroeconomía sana, de las oportunidades que ofrecen la apertura y la globalización y un Estado eficiente" y la necesidad de implementar políticas macroeconómicas que controlen la vulnerabilidad externa, al tiempo que aclaraba que la elaboración de políticas públicas orientadas a un desarrollo integral no se debía confundir con estatismo (Ocampo, 1998).

Estos planteamientos suponen que la apertura del mercado y la inserción de las economías de América Latina (aun en un sistema asimétrico) constituyen el camino más adecuado para lograr un mayor desarrollo, sin tomar en cuenta que la limitación a las ventajas del libre comercio están inscritas en la dinámica centroperiferia. Esta dinámica fue una de las premisas clave en los análisis de la primera CEPAL y de los posteriores estudios sobre el desarrollo realizados desde una perspectiva crítica. Desde aquellas miradas, eran las implicaciones de las relaciones centro-periferia las que hacían necesaria la intervención del Estado en la planificación de la economía, la protección de la industria local y la promoción de desarrollo tecnológico, y para lograr tales metas se promovía un mayor vínculo entre las economías regionales. Asimismo, era la desigualdad entre el centro y la periferia la que impedía o dificultaba la autonomía de las economías de la periferia, que dependían de las divisas provenientes de las exportaciones (de materias primas) para importar bienes de capital y manufacturas, a la vez que debían aceptar el ingreso de empresas extranjeras para adquirir el know-how, a fin de lograr un desarrollo tecnológico autónomo en un mediano plazo. Como ex- 
pusimos en las primeras páginas de este artículo, no sólo no se lograron estos objetivos, sino que la brecha entre el centro y la periferia se ensanchó a partir del profundo endeudamiento de las economías latinoamericanas durante la década de 1980.

Teniendo en cuenta el devenir de la integración entre 1950 y 1980 consideramos que la propuesta de la transformación productiva con equidad, al aceptar la condición de periferia de América Latina, justificaba la implementación de ciertas modificaciones -que se alineaban de modo directo o indirecto con el ajuste estructural-orientadas a lograr una mayor competitividad en los ámbitos regional e internacional por medio de la apertura del mercado para asegurar la mejor inserción posible de las economías de América Latina. Es en esta adaptación mediante la apertura del comercio, sin réplicas al sistema, donde se evidencia un retorno a las premisas neoclásicas y una vinculación con los postulados neoliberales. ${ }^{23}$

Esta resignación a la condición de periferia se contradice con la postura política de la primera $\operatorname{CEPAL}^{24}$ y las iniciativas impulsadas desde el estructuralismo para reducir las asimetrías inscritas en el sistema económico internacional. De hecho, Raúl Prebisch fue uno de los impulsores y primer secretario general de la Conferencia de las Naciones Unidas sobre Comercio y Desarrollo (UNCTAD, 1964), creada en el marco de la onu con el objetivo de regularizar la situación de los países menos desarrollados mediante acuerdos internacionales y de la estabilización de precios. Asimismo, queda claro que la postura de la primera CEPAL acerca del desarrollo no se reducía a factores macroeconómicos y recetas de estabilización, sino que envolvía algunas cuestiones políticas, como la necesidad de fortalecer las relaciones entre los países periféricos para presionar a los países centrales para que se comprometieran con un comercio más justo, que contribuyera

\footnotetext{
${ }^{23}$ En una entrevista realizada a Fernando Fajnzylber (1994) se le preguntó específicamente cuáles eran las relaciones entre la propuesta de transformación productiva con equidad de la CEPAL y los objetivos neoliberales. Fajnzylber declaró que la vinculación era superficial y que había importantes diferencias en la sustancia entre ambas propuestas. De cualquier modo, en ese periodo, la CEPAL no cuestionó la apertura de los mercados, que era justamente una de las premisas del ajuste estructural regulado por el Consenso de Washington y promovido por las instituciones financieras internacionales. Según una síntesis hecha por Bielschowsky (2009: 177), se afirma que durante la etapa neoestructuralista de Fajnzylber "se evaluaron las oportunidades y desafíos para el desarrollo en economías abiertas y con Estados activos pero menos intervencionistas".

${ }^{24}$ No se debe confundir esta posición política con la falta de análisis sistemáticos acerca de la vinculación entre la estructura económica y social y la estructura política, que señalamos en el apartado anterior.
} 
al desarrollo industrial de la periferia, actitud solidaria que en aquel momento se consideraba posible. ${ }^{25}$

Por otra parte, y más allá de nuestras apreciaciones, el giro economicista que caracterizó a la CEPAL de los noventa lo asumió la misma CEPAL a partir del nuevo milenio al plantear la necesidad de apuntar a un desarrollo integral capaz de

\begin{abstract}
dejar de lado la visión uniforme y lineal del desarrollo económico, más evidente en las últimas décadas que propugnaba una agenda única, independiente de las instituciones, de las realidades sociales y económicas, de la historia del desarrollo de cada país y que relegaba al Estado a un papel secundario y subordinado a las decisiones de los mercados, a los que adjudicaba la capacidad de resolver tanto la asignación de los recursos, como las cuestiones distributivas (Machinea et al., 2005: 10. Las cursivas son nuestras).
\end{abstract}

No obstante esta declaración, con respecto a la integración regional debemos señalar que desde la Dirección de División de Comercio Internacional e Integración de la CEPAL se viene impulsando la necesidad de abrirse a acuerdos bilaterales con terceros, sin dejar de lado los procesos de integración subregionales y rescatando el regionalismo abierto como la vía más adecuada para una mejor inserción en el mercado internacional, capaz de generar competitividad y crecimiento (Rosales, 2006). Esta postura se complementa con diferentes investigaciones - publicadas por la misma CEPAL- que señalan la necesidad de liberalizar los mercados de la región (con el objetivo de evitar las discriminaciones en otras zonas, por su aislamiento) teniendo en cuenta la importancia de establecer acuerdos bilaterales con economías más desarrolladas, como lo demuestra el caso de Chile y sus acuer-

${ }^{25}$ En el comunicado de Prebisch acerca del primer encuentro de la UNCTAD con el secretario general de la ONU, expresaba lo siguiente: "La actitud conciliatoria de los países en desarrollo en Ginebra expresa muy bien el ánimo que los ha llevado en esta Conferencia a reunirse en lo que se ha dado a llamar el 'Grupo de los 75' [...]. Por lo demás, hay una cierta tendencia muy comprensible en los países industriales a mirar con su propia óptica los problemas de los países en desarrollo y no con la óptica de estos últimos. Las restricciones que encontró en los primeros tiempos el proceso de industrialización periférica, la renuncia a reconocer el deterioro de la relación de precios del intercambio, las aprensiones con que suele encararse el papel del sector público en los países en desarrollo, son ejemplos, entre muchos otros, de actitudes que se han ido modificando [...]. De la actitud de esos países más avanzados depende ahora en gran parte cómo esa nueva fuerza podrá ejercitarse, qué grado de sacrificio humano se requerirá en este esfuerzo para lograr en el curso de los próximos cincuenta años la nueva utopía de este siglo, esto es, la extirpación de la miseria y sus males inherentes que aún prevalecen para las tres cuartas partes de la humanidad" (Prebisch, 1965: 189-191). 
dos con Estados Unidos (con base en la normativa de Tratado de Libre Comercio), con la Unión Europea y Japón (Vaillant, 2007).

Esta postura se complementa con la sugerencia de relegar las diferencias políticas entre los países del Cono Sur, en tanto la guía de la integración deben ser las tendencias económicas y no tanto las voluntades políticas coyunturales de determinados gobiernos, teniendo como meta el rol protagónico del sector empresarial privado, que hasta el momento no se ha podido conciliar con políticas estatales (Rosales, 2006: 24). Esta apreciación es particularmente interesante, en primer lugar, porque plantea una clara división entre la esfera de lo económico y la esfera de lo político, como si las diferencias políticas no tuvieran asimismo una base económica. Con esto queremos decir que, cualquiera que sea la postura que se asuma, es evidente que el proyecto político-económico de Bolivia no es el mismo que el de Brasil, que las estrategias de Chile no se identifican con el planteamiento del gobierno venezolano, etc., con lo cual no estamos en presencia de meras disidencias políticas, sino de proyectos políticos y económicos nacionales que muestran importantes diferencias. En segundo lugar, se califica de coyuntural al interés de los gobiernos en comparación con los del sector empresarial privado, como si estos últimos elaboraran sus estrategias únicamente a mediano y corto plazos.

De este modo, si bien en la definición de desarrollo integral de la CEPAL parece diferenciarse del punto de vista sostenido durante los noventa, que devuelve al Estado un rol primordial a la vez que subordina al mercado y que plantea asimismo un retorno a la realidad social y a la historia de desarrollo de cada país, los planteamientos acerca de la integración regional siguen orientados por el neoestructuralismo. La omisión de la visión centroperiferia en los análisis actuales de la CEPAL se expresa de modo explícito en la siguiente comparación entre estructuralismo y neoestructuralismo elaborada por Bielschowsky:

En el periodo estructuralista, se señalaban entre otros aspectos las desfavorables relaciones "centro-periferia", el deterioro de los términos de intercambio, el desequilibrio externo y la inflación estructural, la dinámica de sustitución de importaciones, la integración regional y la dependencia. Por su parte, en la etapa neoestructuralista destacan las ideas relativas a la inserción internacional desfavorable y las asimetrías en la era de la globalización, la vulnerabilidad externa y a los ciclos económicos, el regionalismo abierto y las agendas global, regional y nacional (2009: 184). 
¿Por qué se hace referencia al sistema internacional asimétrico y a la inserción internacional desfavorable en lugar de utilizar la terminología centro-periferia? Desde nuestro punto de vista, esto no obedece a una simple actualización de la teoría, sino que es una forma de acomodarse a la agenda global sin generar tensiones ni cuestionamientos acerca de las reglas del sistema internacional. Es decir, al evitar utilizar la concepción de centro y periferia como eje del orden económico y político nacional, regional e internacional se favorece una postura neutral y despolitizada frente al desarrollo, que se reemplaza por una visión que rescata la necesidad y la conveniencia de la apertura comercial y la adaptación al sistema. ${ }^{26}$

En lo relativo al neoliberalismo, entendemos que se ha cuestionado desde diferentes ámbitos, a pesar de su predominio en política económica. ${ }^{27}$ Las metas y objetivos de esta corriente tiene sus bases teóricas en la contrarrevolución neoclásica encabezada por intelectuales como Bela Balassa y Anne Kruegger, en clara confrontación con el sistema de la ISI, la participación del Estado y los mecanismos de protección (Kuntz, 2005). A su vez, los lineamientos políticos y económicos que promueve están emparentados con las políticas neoconservadoras de los gobiernos de Tatcher y Reagan de principio de los años ochenta.

En América Latina el neoliberalismo se consagró por medio del Consenso de Washington (1989), ${ }^{28}$ que alcanzó un éxito rotundo -en tanto logró imponer al ajuste como inevitable y profundizó la liberalización de los mercados de la región- aunque se plantee (como lo hace Love, 2005) que a raíz del fracaso o de los magros resultados de la aplicación de medidas neoliberales, se hace necesario volver a perspectivas anteriores, como el es-

${ }^{26}$ Nuestra reflexión coincide en buena medida con las apreciaciones de Nahón et al.: "En suma, en esta etapa, la CEPAL abandonó casi por completo la cuestión del desarrollo como núcleo central de su reflexión y de sus propuestas y se focalizó fundamentalmente en la estabilización y el ajuste de la economía latinoamericana, priorizando una visión de corto plazo. [...] Este nuevo enfoque, si bien mantenía cierta distancia teórica con la nueva ortodoxia y contenía algunos ejemplos novedosos propios del remozado estructuralismo, se parecía peligrosamente a aquélla, acercando a la CEPAL a la corriente dominante en las ciencias sociales: la economía neoclásica" (2006: 360).

${ }^{27}$ En los discursos de algunos gobernantes latinoamericanos, sobre todo en aquellos dirigidos en oposición al ALCA, o al relanzamiento del Mercosur (Katz, 2006); en el ámbito académico; en espacios como el Foro Social Mundial, etcétera.

${ }^{28}$ Algunos de los objetivos clave de este Consenso son los siguientes: disciplina fiscal; reformulación de las prioridades en el gasto público a favor de la salud primaria, la educación y la infraestructura; reforma impositiva; liberalización financiera; unificación de la tasa de cambio; apertura comercial; acceso a inversiones extranjeras; privatización de las empresas estatales; desregulación en aras de la competencia y facilitación de los derechos de propiedad (Williamson, 1993, en Orlansky, 2006: 10). 
tructuralismo o la dependencia. La presencia del neoliberalismo se afianza en Latinoamérica mediante la firma de los Tratados de Libre Comercio bilaterales con Estados Unidos, que concretan algunas de las metas del ALCA (Área de Libre Comercio de las Américas) y los BIT entre los mismos países de la región, lo cual deja en evidencia la preponderancia del bilateralismo en desmedro del multilateralismo que debería ser el núcleo del proceso de integración.

Un claro ejemplo lo constituyen las relaciones entre Brasil y Estados Unidos, que dan cuenta de que la economía más importante de la región está muy interesada en acercase al país del Norte, como lo demostró en la última ronda de negociaciones de la OMC en Doha, marcando una clara distancia con los otros países periféricos y distanciándose del Mercosur. Por otra parte, a partir del gobierno de George W. Bush, ambos países estrecharon relaciones no sólo con base en los vínculos en materia comercial y de inversiones, sino planteando esta relación bilateral como eje del proyecto mundial de impulso de biocombustibles, en el marco de la planificación de producción de energías alternativas del gobierno de Estados Unidos. ${ }^{29}$

\subsubsection{Las empresas translatinas y la reproducción de la lógica de las multinacionales en el Mercosur}

Con respecto al capital multinacional, es notable el modo en que este tipo de empresas se han desplegado en la región, generando con ello una importante competencia entre países y sectores económicos, que atentan contra la complementación (de acuerdo con una visión estructuralista), pero que son capitales necesarios y que constituyen una oportunidad para el crecimiento (según una visión neoestructuralista). Un claro ejemplo es la dinámica de las industrias automotrices, sector en el cual se han generado importantes conflictos sindicales, empresariales y productivos, tanto dentro de Brasil y Argentina como en las controversias establecidas entre ambos países (Tavares, 1998; Schvarzer, 2001). Este sector ha permitido evidenciar la capacidad de las multinacionales para atravesar la lógica de la integración des-

${ }^{29}$ El proyecto se encuentra en una nota de prensa en la página del Departamento de Estado de los Estados Unidos (Departamento Oficina del Portavoz, 20 de noviembre de 2008), donde se enuncian los acuerdos entre grupos empresariales brasileños y estadounidenses y lo relativo a la producción de etanol. También se puede consultar una nota de la agencia de noticias EFE (7 de febrero de 2007) y Zibechi (2007). Con respecto al impulso de la producción de biocombustibles en África, véase vTV (16 de octubre de 2007). 
cartando la posibilidad de verdadera complementación, generando en cambio una dinámica alejada completamente de la posibilidad de conformar una industria nacional y regional capaz de imponer condiciones al capital multinacional. ${ }^{30}$

Esto se percibe, asimismo, en los conflictos Uruguay-Argentina ocasionados por la instalación de la empresa multinacional Metsae-Botnia dedicada a la industria del papel y la celulosa. Esta actividad genera importantes niveles de contaminación, justamente por eso es complicado instalarlas en países centrales, motivo que las lleva a expandirse hacia la periferia (Katz, 2006: 43).

Tales procesos no hacen más que confirmar el poder que ha adquirido el capital multinacional en los ámbitos nacional y regional, resultando muy compleja la imposición de límites, lo cual habilita una suerte de laissez faire en cuanto a condiciones para la IED. Este pase libre al capital multinacional lo impulsa básicamente el complejo Wall Street-Tesoro de los Estados Unidos (Félix, $1998)^{31}$ y lo sustentan los intereses de las élites de poder del centro y la periferia (en este caso la de América Latina), que se encuentran lejos de una toma de conciencia acerca de las consecuencias a mediano y largo plazos en cuanto al costo social, político e incluso ambiental generados por estas empresas, más allá de los intereses personales o de grupo. ${ }^{32}$ El predominio de los intereses de un grupo minoritario se percibió como aspecto negativo en la puesta en práctica de la ALAC, pero este aspecto casi no se tiene en cuenta en los análisis actuales sobre el proceso de integración. ${ }^{33}$

30 "La creación del Mercosur significa un gran negocio para las grandes empresas, pero sobre todo para las multinacionales. Las empresas locales [automotrices argentinas] Ciadea o Sevel sólo podrían sobrevivir en un mercado cerrado sobre la base de incorporar tecnología de segunda mano, vía la adquisición de licencias a automotrices europeas (Renault y Fiat-Peugeot). El tamaño del mercado interno era su límite y se beneficiaban hasta ahora de la falta de competencia dado que el tope histórico de 550,000 autos-año, no justificaba grandes inversiones" (Nuñez, 2004).

${ }^{31}$ Este autor es claro cuando manifiesta que el sistema de Bretton Woods tuvo como uno de sus objetivos la expansión de las empresas transnacionales, capaces de evadir controles de capital por medio de la fijación de precios de transferencia, a la vez que permitió a las empresas nacionales llevar a cabo una facturación ficticia.

${ }^{32} \mathrm{La}$ alianza entre sectores dominantes del centro y de la periferia constituyó parte de las explicaciones elaboradas por los teóricos de la dependencia (Gunder y Johnson, 1970; Dos Santos, 1972). No obstante, desde tales lecturas aparentemente se otorgaba un rol pasivo a los sectores dominantes en la periferia (en general asociados a las burguesías nacionales) que fue criticado por Furtado (1971) y Fernandes (1979), entre otros. En este sentido, la conceptualización de élite del poder de Wright Mills (1978) resulta bastante pertinente para dar cuenta de las alianzas nacionales de los grupos con mayor acceso a la toma de decisión política, económica y militar.

${ }^{33}$ Una excepción es el trabajo de Falero (2006), que si bien no hace un análisis específico sobre integración regional, menciona la importancia de la conectividad y los flujos en las decisiones dentro del Mercosur. 
Vale aclarar que la invisibilidad de las alianzas entre élites privilegiadas subyacente en la dinámica de las empresas en el proceso de integración y también en la toma de decisión en el ámbito del Mercosur, muchas veces corresponde con las perspectivas teóricas presentes en los estudios sobre integración regional.

Uno de los indicios que nos conducen a esta aseveración es la postura sobre el supuesto potencial de las empresas translatinas tanto para el desarrollo como para la integración de la región. Consideramos necesario, en primer lugar, desnaturalizar el término translativa, que a primera vista parecería nombrar a una empresa compuesta por capitales de diferentes países latinoamericanos (si no todos) que se extiende hacia otros mercados (por ejemplo Europa, América del Norte, Asia, etc.). No obstante, siguiendo a la CEPAL, esta nominación se aplica a empresas como Vale do Rio Doce, empresa brasileña que compró por 17,528 millones de dólares la minera Inco de Canadá; o la mexicana Cemex Sab que adquirió la empresa australiana Rinker Group Ltd., del sector construcción, por 14,627 millones de dólares y también la argentina Techint que compró la mexicana Hylsamex (sector acero) por 2,581 millones de dólares a inversores locales (CEPAL, 2007: 40).

Estos datos llevan a la CEPAL a aseverar que por primera vez la inversión de capitales latinoamericanos (40,620 millones de dólares) se acerca a la IED en la región ( 72,440 millones), abriendo expectativas y razonamientos que concluyen en que América Latina se puede considerar un mercado capaz de expandirse hacia el exterior, lo cual lleva a la suposición de que se trata de un espacio en pleno desarrollo y crecimiento. Los datos también aclaran las corrientes de inversión directa en el exterior (durante el año 2006) de Brasil (28,202 millones de dólares) y de Argentina (2,008 millones), pero Uruguay y Paraguay no aparecen como inversores en el extranjero (CEPAL, 2007). Tanto la ausencia de las economías más pequeñas del Mercosur, como la brecha entre la IED de Brasil y Argentina, dejan entrever una vez más la asimetría que caracteriza al bloque. Con base en estas afirmaciones, y teniendo en cuenta lo analizado en el apartado anterior, entendemos que la CEPAL sigue considerando la inversión extranjera como una aportación indiscutible, más allá de las consecuencias que ha tenido la IED en la región y de los análisis que han demostrado la inconveniencia de la apertura incondicional a este capital.

Una de las suposiciones más frecuentes con respecto a las grandes empresas, es que se presume que por tener su origen en 
el marco jurídico y territorial de un Estado-nación, representan los intereses del mismo. Desde nuestra perspectiva -y teniendo en cuenta las estrategias desplegadas por las grandes empresas en la región a partir de la década de los cincuenta- las empresas responden a los intereses de los empresarios y accionistas, más que a los de la nación o la región, aunque éstos pueden coincidir coyunturalmente. En efecto, lo que muestran los hechos es que son las grandes empresas las que terminan por imponer sus intereses y estrategias a la dinámica regional, socavando las bases políticas de los acuerdos.

Constituyen claros ejemplos los ya mencionados conflictos en torno a las automotrices y las papeleras en el Mercosur, a lo que podemos agregar las recientes tensiones entre Argentina y Venezuela por la expropiación de algunas subsidiarias de la empresa Techint por parte del gobierno venezolano. ${ }^{34}$ La mayor parte de los periódicos argentinos publicó la noticia como si Techint representara los intereses nacionales a la vez que se criticaba al socialismo del gobierno venezolano por perjudicar a las empresas de argentinas. Poco se dijo acerca de las transacciones necesarias para llevar a cabo una expropiación y sobre el monto que efectivamente pagó el gobierno venezolano. Poco se ha publicado en los medios masivos más influyentes acerca de los intereses y la historia de Techint. ${ }^{35}$

El saldo fue el pedido por parte de la Asociación Empresaria Argentina, la Cámara Argentina de Comercio, la Unión Industrial Argentina (UIA) y otras entidades del rubro de rechazar el ingreso de Venezuela al Mercosur. En las declaraciones de la UIA queda clara la visión de Mercosur que se cultiva:

${ }^{34}$ Vale aclarar que la historia de las expropiaciones en América Latina está estrechamente vinculada al proceso de expansión del capitalismo monopólico hacia la región en un contexto de guerra fría desestabilizado por la Revolución cubana. Los casos paradigmáticos de expropiación y nacionalización de empresas multinacionales (en su mayoría estadounidenses) se dieron durante el gobierno de Arbenz en Guatemala (19511954), el de Goulart en Brasil (1961-1964), el de Velasco Alvarado en Perú (1968-1975) y el gobierno de Allende en Chile (1970-1973).

${ }^{35}$ La primera parte de la indemnización que recibió Techint por la expropiación de Siderúrgica Orinoco (radicada en Venezuela) es de 400 millones de dólares y fueron depositados en Alemania. La sede de Techint es Luxemburgo (uno de los principales paraísos fiscales según el Grupo de los 20) y el capital inicial de la empresa es italiano y alemán, con predominio del primero. Techint controla un centenar de empresas de las cuales sólo cuatro están radicadas en Argentina y menos de un tercio de los 40,000 puestos de trabajo de la empresa en todo el mundo se crearon en Argentina. El resto son empresas de Italia, Estados Unidos, China, Canadá, Reino Unido, Chile, México, Japón, Rumania, Portugal, Liechstenstein, Uruguay, Colombia, Guatemala, Noruega, Irlanda, Singapur, Indonesia, Islas Vírgenes Británica y Venezuela (Verbitsky, 2009). 
Las decisiones sistemáticamente adoptadas por el gobierno venezolano -señaló la UIA- son contrarias a estas condiciones [las de políticas comunes que deben tener los socios regionales], mostrando una posición de absoluta asimetría respecto a las ofrecidas por los restantes países del blo$q u e$, poniendo en riesgo el proceso de integración regional, y representan un cambio sustancial respecto a las circunstancias bajo las cuales el Congreso argentino aprobó el ingreso de Venezuela al Mercosur (Perfil, 27 de mayo de 2009. Las cursivas son nuestras). ${ }^{36}$

En otro periódico se publicó el pedido formal de dicha entidad al gobierno: "La UIA solicita al gobierno argentino que arbitre los esfuerzos tendientes a revertir esta situación y defender los legitimos intereses de nuestro país en el exterior" (Clarín, 23 de mayo de 2009). ${ }^{37}$

Dos cuestiones surgen de estas declaraciones. La primera es que se habla de asimetría en este caso, pero no se define como asimétrica la compra de empresas argentinas por grandes grupos brasileños, como veremos a continuación. La otra cuestión es que este tipo de reflexión corresponde con aquellas percepciones que sostienen que buena parte de las actuales limitaciones del proceso de integración se deben a las tensiones entre los modelos integradores surgidos o reformulados en el marco del regionalismo abierto (Comunidad Andina de las Naciones y Mercosur) y las nuevas propuestas de integración, como la Comunidad Sudamericana de Naciones (CSAN) y el Alba (Alternativa Bolivariana para las Américas), marcando estos últimos un retorno hacia políticas económicas nacionalistas, que finalmente condujeron a la politización de la economía exterior, lo cual obstaculiza en buena medida la posibilidad de conciliar las diferentes alternativas de integración (Motta y Ríos, 2007). Según esta visión, la idea sería circunscribirse a impulsar unas relaciones interregionales limitadas a acuerdos comerciales y de inversión, centradas en lo económico, como si esto no implicara por sí mismo un posicionamiento político.

${ }^{36}$ El tono que adquirió el tema de la expropiación y el amplio espacio que se le otorgó en los medios masivos más importantes de Argentina, se debe a que a fines de junio se llevarían a cabo las elecciones de diputados y senadores, con lo cual el caso Techint fue utilizado por la oposición para demostrar sus diferencias con el oficialismo.

${ }^{37}$ Finalmente, el representante de Argentina ante el Mercosur, Carlos Chacho Álvarez planteó que de ningún modo se pedirá la no admisión de Venezuela, en la que se viene trabajando hace algunos años, ya que la única condición inicial para formar parte del Mercosur es ser un gobierno democrático constitucional (La Voz del Interior, 30 de mayo de 2009). Con respecto al gobierno argentino, en una primera instancia pidió al gobierno venezolano cumplir con el acuerdo al que habían llegado con Techint. No obstante, en el transcurso de dos semanas, el gobierno ha endurecido su postura respecto de Techint, diciendo que lo que importa es que no recorten empleos en Argentina, más allá de las pérdidas del grupo en Argentina o en Venezuela (Clarín, 6 de junio 2009). 
Asimismo, nos preocupa esta visión de las transnacionales como indice de crecimiento y proyección de América Latina, debido a que más allá de los indicadores económicos, representan un sector reducido al interior de dos o tres países de América Latina (los empresarios y accionistas implicados en las compras, más allá de la capacidad de generar fuentes laborales), a la vez que reproduce en la región la dinámica de las empresas multinacionales, con la única diferencia de que son capitales originados en la región (lo cual, por cierto, es difícil de afirmar, conociendo las estrategias de fusión, compra y venta permanentes en el funcionamiento normal de estas empresas). ${ }^{38}$

¿Las translatinas promueven la integración y complementación de las industrias y empresas regionales o tienden más bien a expandirse a costa de la integración (nacional y regional), en pos del predominio de una(s) empresa(s) sobre otra(s)? Muestra de ello es la compra de empresas argentinas por parte de grandes grupos brasileños, ${ }^{39}$ a la vez compuestas por capitales multinacionales: Brahama, que forma parte del grupo multinacional In Bev compró la cervecera Quilmes por 1,800 millones de dólares; Petrobrás (compañía brasileña de petróleo compuesta mayormente por capitales nacionales, pero que también posee capitales multinacionales) compró Pecom por 1,130 millones; a su vez Acindar compró en 160 millones de dólares Belgo Mineira, que también forma parte de un conglomerado multinacional ${ }^{40}$ (Clarín, 2 de febrero de 2005).

${ }^{38}$ Un claro ejemplo es el caso de Vale do Rio Doce, que no sólo posee capitales brasileños, sino que parte importante de sus acciones pertenecen a empresas estadounidenses y alemanas: Capital Guardian Trust Co., Capital Research \& Management Inc., FMR Corp. (Fidelity Investments), Janus Capital Corp., Putnam LLC, Wellington Management Co., Deutsche Bank g (Transnationale \& Co, 2008).

${ }^{39}$ En primer lugar queremos aclarar que las cursivas se deben a que los capitales y accionistas de esas empresas no siempre son nacionales, sino que, por el contrario, se caracterizan porque son multinacionales. En el periodo 1992-1996 Brasil invirtió 351.8 millones de dólares en la industria manufacturera en otros países de la región, siendo este sector el más dinámico (agrupaba $62 \%$ de la IED total) y se dirigió sobre todo a Argentina, país que se caracteriza por su mano de obra calificada (y accesible), a diferencia de otros Estados de la zona. Con respecto al sector automotriz, que también es uno de los preferidos por la IED brasileña por su dinamismo, las inversiones se hicieron en autopartes y por ende de una envergadura mediana o chica para el sector. Lo que se aprovechó en este caso fue la cercanía del cliente (debido a que no era necesario instalarse a fabricar en otro lado, en el marco de las ventajas otorgadas por el Mercosur) (Gobierno de la Nación Argentina, 2001).

${ }^{40}$ Belgo Mineira pertenece a Arcelor Mittal, empresa de los Países Bajos, que tiene filiales en China, las Antillas Holandesas, Bulgaria, Ucrania y Estados Unidos. A su vez, Petrobrás, además de contar con capitales nacionales, tiene accionistas de empresas norteamericanas como Capital Research \& Management Inc., Mellon Financial Corp., Morgan Stanley, Putnam LLC y Wellington Management Co.; con respecto a Brahama, 
Por último señalamos que a pesar de la importante y creciente afluencia a la región de capitales extranjeros europeos y asiáticos, las compañías de Estados Unidos siguen siendo una fuerza económica decisiva para América Latina en cuanto a acceso a mercados y oportunidades de inversión (Kay, 1998). Esto se puede observar en las cifras de la IED en América Latina para el año 2006, en las cuales se da cuenta que de las 50 empresas multinacionales instaladas en la región, las dos primeras en ventas totales fueron WalMart (21,124 millones de dólares) y General Motors Corp. (19,965 millones). ${ }^{41}$ La suma de la ganancia en ventas de estas dos grandes empresas duplica prácticamente la suma de la IED en los países del Mercosur para el año 2006, que alcanzó aproximadamente 25,055 millones de dólares (CEPAL, 2007). Algunos funcionarios estadounidenses, como el secretario de Comercio, Carlos Gutiérrez), remarcan la importante presencia de esa economía en la región: "las empresas estadounidenses invirtieron 353 mil millones de dólares en América Latina y el Caribe en el año 2005. Sus filiales emplean a 600 mil personas. En el 2006, las exportaciones estadounidenses aumentaron 12.7\% y las importaciones 10.5\%" (Gutiérrez, en Habel, 2007: 12).

Con respecto al proyecto de integración continental, al no firmarse todos los tratados para dar vigencia al ALCA tal como se había previsto, el gobierno norteamericano se ha ocupado de firmar Tratados de Libre Comercio con cada uno de los países de la región, que afectan tanto la IED nacional, como a los proyectos de integración subregionales.

\section{Reflexiones finales}

Cerramos este trabajo con algunos cuestionamientos acerca del rol del capital multinacional en la ALALC y el Mercosur y reflexionado acerca de la coyuntura actual del proceso de integración de América Latina en general.

pertenece al conjunto In Bev, cuyos principales accionistas son: Capital Research \& Management Inc., Morgan Stanley, Oppenheimer Capital, Putnam LLC, Rowe Price Associates Inc. y JP Morgan Chase \& Co. (EE.UU.), Deutsche Bank AG (Alemania), In Bev, s.A. (Bélgica) y Lemann, Jorge Paulo (Brasil) (Transnationale \& Co, 2008).

${ }^{41}$ La crisis económica y financiera desatada a mediados de 2008 cambió el panorama de la economía estadounidense y de sus empresas. Si bien no es pertinente abordar esta temática en el presente estudio, consideramos que algunas apreciaciones interesantes acerca de la crisis son las de Petras (2009), Krugman (2009) y una síntesis publicada por Página 12 (10 de marzo de 2009). 
De acuerdo con las características asumidas por el capital multinacional en el Mercosur (que guardan una estrecha relación con lo acontecido con la ALALC) y teniendo en cuenta que nos acercamos a los 50 años de intentos de integración en América Latina, nos interesa rescatar algunas preguntas recurrentes durante la década de los sesenta: ¿̇la IED y el capital multinacional en particular, se pueden considerar motores de desarrollo en el contexto latinoamericano, bajo qué condiciones?, ¿implica beneficios por sí misma la liberalización del comercio y la liberalización del flujo de capitales?, ¿quiénes se benefician en mayor medida de esta integración?, ¿qué grupos influyen en mayor medida de modo directo o indirecto en la toma de decisión en el ámbito regional?

Con respecto al proceso de integración de América Latina en el nuevo milenio, ha habido importantes avances regionales, como la conformación del Banco del Sur (Buenos Aires, diciembre de $2007)^{42}$ que parece constituir una iniciativa para contribuir a un desarrollo autónomo, orientado a reducir las asimetrías y la dependencia respecto de capitales extranjeros, especialmente del financiamiento del Banco Mundial, el Fondo Monetario Internacional y el Banco Interamericano de Desarrollo. No obstante, estamos de acuerdo con las advertencias de Toussaint (2007) acerca de que debemos estar atentos ante la posible reproducción de las premisas macroeconómicas que caracterizaron al ajuste estructural en el funcionamiento del Banco, si reduce su misión al fomento del mercado de capitales financieros regionales. También se han estrechado los vínculos entre los países de América del Sur, como lo demuestra la resolución de conflictos en el marco de la Unasur, a pesar de la evidente dispersión de proyectos de integración

${ }^{42}$ El Banco del Sur, proyecto firmado por los presidentes de Argentina, Néstor Kirchner; de Bolivia, Evo Morales; de Brasil, Luis Inácio Lula da Silva; de Ecuador, Rafael Correa; de Paraguay, Nicanor Duarte Frutos; de Venezuela, Hugo Chávez y Tabaré Vázquez de Uruguay (que lo firmaría al día siguiente), tendrá por objeto financiar el desarrollo económico y social de los países de la Unión Suramericana (Unasur), que se integren como miembros, en forma equilibrada y estable, haciendo uso del ahorro intra y extra regional; fortalecer la integración, reducir las asimetrías y promover la equitativa distribución de las inversiones entre los socios de la entidad. Según sus promotores, esta institución se considera fundamental para integrar la región, ya que fomentará el acceso al financiamiento y permite dar un paso importante para la autonomía financiera del Mercosur. A su vez, se propone la vigencia de una moneda única. El Banco del Sur debe ser el primer paso para atraer inversiones, ser autosostenible y gobernarse conforme a criterios profesionales de eficiencia financiera, para garantizar que su actuación no resulte en dispendios adicionales, sino en la generación de nuevos recursos para ser reinvertidos en los países miembros. También se plantea que los países tendrán representación igualitaria en los órganos del banco, asegurando su funcionamiento democrático (Infobae, 10 de diciembre de 2007). 
como el Mercosur, la Comunidad Andina de las Naciones, la Alternativa Bolivariana para las Américas y los tratados bilaterales de comercio de algunos países con Estados Unidos. Si bien existen interacciones entre cada una de estas instituciones, siguen siendo organismos separados.

En el ámbito continental se perciben ciertas modificaciones en las relaciones de América Latina con Estados Unidos, lo cual se puso en evidencia en las declaraciones realizadas por los diferentes mandatarios en la Quinta Cumbre de las Américas (abril de 2009), así como en la revocación de la resolución de la oEA que impedía el ingreso de Cuba a la institución (3 de junio de 2009). No obstante, desde nuestra perspectiva, habría que prestar atención al eje Estados Unidos-México-Brasil, que se viene reforzando desde el último gobierno de George W. Bush y a partir de la actual gestión de Barack Obama. Este eje se asienta en aspectos de seguridad (en el caso de México) y económicos (en el caso de Brasil), que a su vez implican compromisos políticos. Con respecto a las relaciones de Estados Unidos con Brasil, la gran apuesta es en la producción conjunta de biocombustibles, lo cual implica de por sí ciertas tensiones entre Brasil, Venezuela y Bolivia que han asentado sus proyectos políticos y económicos en los hidrocarburos y poseen importantes intereses en la región.

Entendemos que es en la dimensión política donde se ponen en evidencia los diferentes proyectos y estrategias económicas, por eso consideramos que debería apuntarse a una búsqueda conjunta de una definición de desarrollo que trascienda los postulados que reducen el desarrollo al crecimiento económico y que por ello tienden a diluir sus bases político-críticas. La primera CEPAL fue un disparador de una postura crítica de América Latina frente a las desigualdades inscritas en el sistema internacional. Esta perspectiva la radicalizaron los dependentistas e intelectuales de perspectiva crítica, confirmando las consecuencias negativas de la reproducción del capitalismo en la periferia, no sólo en lo económico, sino también en el plano político, cultural y social.

La actual coyuntura de América Latina demanda una noción de desarrollo e integración que supere el reduccionismo economicista y asuma de modo explícito la vinculación entre lo político y lo económico, descartando la neutralidad. No sirve de nada apelar a la despolitización de los conflictos o la desideologización de los mismos, cuando ello es parte de la historia y del desarrollo económico, social y político de las sociedades de América 
Latina. Debemos intentar encontrar espacios que permitan la puesta en común y el diálogo, que apunten a resolver los problemas de la mayoría y superen los intereses de las minorías privilegiadas. Si falla esta tarea, es probable que el Mercosur se consolide como un espacio favorable para la reproducción de la lógica de las empresas multinacionales favoreciendo a sectores minoritarios dentro de las economías y las sociedades de América Latina, contribuyendo a su vez a profundizar la brecha con los países centrales, perpetuando las relaciones centro-periferia.

\section{Bibliografía}

Baran, Paul y Paul Sweezy (1974), El capital monopolista. Ensayo sobre el orden económico y social de los Estados Unidos, Siglo XXI, Buenos Aires.

Barnet, Richard y Ronald Müller (1974), Poder global: a força incontrolável das multinacionais, Record, Río de Janeiro.

Beigel, Fernanda (2006), "Vida, muerte y resurrección de las teorías de la dependencia", en Fernanda Beigel, Alfredo Falero, José G. Gandarilla Salgado, Nestor Kohan, Ladislao Landa Vásquez, Carlos E. Martins, Cecilia Nahón, Corina Rodriguez Enríquez y Martín Schorr (autores), Crítica y teoría en el pensamiento social latinoamericano, Colección Becas de Investigación, ClACSO, Buenos Aires, pp. 287-326.

Bielschowsky, Ricardo (2009), "Sesenta años de la CEPAL: estructuralismo y neoestructuralismo", Revista de la Cepal 97, Santiago, pp. 173-194, [en línea] http://www.eclac.org/ publicaciones/xml/0/35860/RVE97Bielschowsky.pdf, 30 de abril de 2009.

Blomström, Magnus y Björn Hettne (1990), La teoría del desarrollo en transición, Fondo de Cultura Económica, México.

Caputo, Orlando y Roberto Pizarro (1975) Imperialismo, dependencia y relaciones económicas internacionales, Amorrortu, Buenos Aires. 
Cardoso Fernando H. y Enzo Faletto (1973), Dependencia y desarrollo en América Latina, Fondo de Cultura Económica, México.

CEPAl (Comisión Económica para América Latina) (1959), El Mercado Común Latinoamericano, CEPAL-ONu, México.

CEPAL (Comisión Económica para América Latina) (1969), El pensamiento de la CEPAL, CEPAL-Editorial Universitaria, Santiago de Chile.

CEPAl (Comisión Económica para América Latina) (1990), "Transformación productiva con equidad", Revista de la CEPAL, Santiago de Chile, marzo, http://www.eclac.cl/ publicaciones/xml/1/4371/lcg1601e.htm.

CEPAL (Comisión Económica para América Latina) (1994), "El regionalismo abierto en América Latina y el Caribe: la integración económica al servicio de la transformación productiva con equidad" (LC/G 1801), Santiago de Chile, http://www.eclac.cl/publicaciones/xml/7/4377/ $\operatorname{lcg} 1801$ e.htm.

CEPAL (Comisión Económica para América Latina) (2007), La inversión extranjera en América Latina y el Caribe 2006, Documento informativo, CEPAL, Santiago de Chile.

Clarín (2005), "Brasil invirtió US\$ 3.000 millones en la compra de firmas argentinas", 2 de febrero, http://www.clarin.com/ diario/2005/05/02/elpais/p-01601.htm.

Clarín (2009), "Enérgico rechazo empresarial a nuevas estatizaciones de Chávez", 23 de mayo, http://www.clarin.com/ diario/2009/05/23/elpais/p-01924603.htm.

Clarín (2009), "El Grupo Techint sale a responder tras el duro ataque de Néstor Kirchner", 6 de junio, http://www.clarin. com/diario/2009/06/04/um/m-01932800.htm.

Colacrai, Miryam (1992), "Perspectivas teóricas en la bibliografía de la política exterior argentina”, en R. Russell (ed.), 
Enfoques teóricos y metodológicos para el estudio de la política exterior, GEL-RIAL, Buenos Aires, pp. 19-52.

Declaración de los economistas latinoamericanos (1970), en André Gunder Frank, James A. Cockroft y Dale Johnson (eds.), Economía política del subdesarrollo en América Latina, Signos, Buenos Aires, pp. 369-375.

Dos Santos, Theotonio (2002), La teoría de la dependencia. Balance y perspectivas, Plaza \& Janés, Buenos Aires.

EFE (2007), "Brasil y EEUU anuncian cooperación para producir biocombustibles", 7 de febrero, http://www.periodistadigital. com/economia/object.php?o $=570626$.

Falero, Alfredo (2006), "Un paradigma renaciente de América Latina: una aproximación sociológica a legados y desafíos de la visión centro-periferia”, en Fernanda Beigel, Alfredo Falero, José G. Gandarilla Salgado, Néstor Kohan, Ladislao Landa Vásquez, Carlos E. Marins, Cecilia Nahón, Corina Rodríguez Enríquez y Martín Schorr (autores), Crítica y teoría en el pensamiento social latinoamericano, ClACso, Buenos Aires, pp. 217-286.

Fajnzylber, Fernando (1994), "La CEPAL y el neoliberalismo", $R e$ vista de la CEPAL, 52, Santiago, pp. 207-210.

Félix, David (1998), "La globalización del capital financiero", Revista de la CEPAL, núm. extraordinario, Santiago, pp. 139154.

Fernandes, Florestán (1979), Mudanças sociais no Brasil, Sao Paulo-Rio de Janeiro, Difel.

Ferrer, Aldo (1976), Economía internacional contemporánea. Texto para latinoamericanos, Fondo de Cultura Económica, México.

Ferrer, Aldo (1998), Hechos y ficciones de la globalización: Argentina y el Mercosur en el sistema internacional, Fondo de Cultura Económica, México. 
Fontoura Costa, José (2006), "Proteçao e promoçao do investimento estrangeiro no Mercosul -uma ferramenta para a implementaçao de un bom clima de investimentos?, Revista Brasileira de Politica Internacional, 49 (2), Instituto Brasileño de Política Internacional, Brasilia, pp. 60-77.

Ffrench-Davis, Ricardo, Óscar Muñoz y José Palma (2000), "Las economías latinoamericanas 1950-1990”, en Leslie Bethell (comp.), Historia de América Latina. Economía y sociedad desde 1930, t. XI, Crítica, Barcelona.

Fuentes, Juan A. (1994), “El regionalismo abierto en América Latina y el Caribe. La integración económica al servicio de la transformación productiva con equidad", Revista de la CEPAL, 53, Santiago, pp. 81-89.

Furtado, Celso (1971), El poder económico: Estados Unidos y América Latina, CEAL, Buenos Aires.

García Lupo, Rogelio (1971), Contra la ocupación extranjera, Editorial Centro, Buenos Aires.

Grunwald, Joseph, Miguel Wionczek y Martin Carnoy (1973), La integración económica latinoamericana y la política de Estados Unidos, CEMLA, México.

Gunder Frank, André (1970), "El desarrollo del subdesarrollo", en André Guder Frank, James Cockroft y Dale Johnson (eds.), Economía política del subdesarrollo en América Latina, Signos, Buenos Aires, pp. 27-42.

Habel, Janette (2007), “El 'patio trasero’ se emancipará. Nuevo desafío regional a Estados Unidos”, Le Monde Diplomatique, diciembre, http://www.eldiplo.com.pe/desafio_ regional_a_estados_unidos.

Herrera, Felipe (1970), "Aspectos institucionales del proceso latinoamericano de integración", en Osvaldo Sunkel (dir.), Integración política y económica: el proceso europeo y el problema latinoamericano, Editorial Universitaria, Santiago de Chile, pp. 311-320. 
Huberman, Leo y Paul Sweezy (1973), Teoría de la política exterior norteamericana, Merayo, Buenos Aires.

Infobae (2007), "Los presidentes de la región lanzaron el Banco del Sur", 10 de diciembre, http://www.infobae.com/notas/ nota.php? Idx $=353179 \& I d x S e c c i o n=200803$.

Johnson, Dale (1970), “Dependencia, desnacionalización del desarrollo y sistema internacional", en Andre Guder Frank, James Cockroft y Dale Johnson (eds.), Economía política del subdesarrollo en América Latina, Signos, Buenos Aires, pp. 93-132.

Katz, Carlos (2006), El rediseño de América Latina: ALCA, Mercosur y Alba, Luxemburg, Buenos Aires.

Kay, Cristóbal (1998), "Estructuralismo y teoría de la dependencia en el periodo neoliberal. Una perspectiva latinoamericana”, Nueva Sociedad, 158, Buenos Aires, pp. 100-119.

Kerner, David (2003), "La CEPAL, las empresas transnacionales y la búsqueda de una estrategia de desarrollo latinoamericana", Revista de la CEPAL, Santiago, 79, pp. 85-99.

Krugman, Paul (2009), "Rescatar a incompetentes", http:// www.rebelion.org/, 20 de febrero.

Kuntz Ficker, Sandra (2005), "From structuralism to the new institutional economics: the impact of theory on the study of foreign trade in Latin America", Latin American Research Review, 40 (3), Texas University Press, Austin, pp. 145-162.

La Voz del Interior, "Buscan postergar el ingreso de Venezuela al Mercosur", 30 de mayo, http://www.lavoz.com.ar/09/05/ 30/secciones/economia/nota.asp? nota_id $=520918$.

Love, Joseph (2005), “The rise and decline of economic structuralism in Latin America: New dimensions", Latin American Research Review, 40 (3), Texas University Press, Austin, pp. 145-162. 
Lusting, Nora (1988), "Del estructuralismo al neoestructuralismo: la búsqueda de un paradigma heterodoxo", Colección de estudios Cieplan, 23, Corporación de Estudios para América Latina, Santiago, pp. 35-50.

Machinea, José Luis, Alicia Bárcena y Arturo León (coords.) (2005), Objetivos de desarrollo del milenio: una mirada desde América Latina y el Caribe, CEPAL, Santiago.

Motta Veiga, Pedro y Sandra Ríos (2007), “O regionalismo pósliberal, na América do Sul: origens, iniciativas e dilemas", Series CEPAL Comercio Internacional, 82, Santiago, http:// www.eclac.org/publicaciones/x ml/5/30045/ S82CI_L2776e_P_Oregionalismo_pos_liberal_America_do_Sul.pdf

Myrdal, Gundar (1964), Teoría económica y regiones subdesarrolladas, Fondo de Cultura Económica, México.

Nahón, Cecilia, Corina Rodríguez Enríquez y Martin Schorr (2006), "El pensamiento latinoamericano en el campo del desarrollo del subdesarrollo", en Fernanda Beigel, Alfredo Falero, José G. Gandarilla Salgado, Néstor Kohan, Ladislao Landa Vásquez, Carlos E. Marins, Cecilia Nahón, Corina Rodríguez Enríquez y Martín Schorr (autores), Crítica y teoría en el pensamiento social latinoamericano, Clacso, Buenos Aires, pp. 217-286.

Nicolau, Sergio (1968), La inversión extranjera directa en los países de la ALALC: estudio descriptivo del tratamiento al capital foráneo, ALALC, México.

Nuñez, Juan C. (2004), “El entrevero. La relación laboral en el Mercosur: convivencia o matrimonio infeliz", Primer Congreso Internacional del Mercosur convocado y organizado por el Colegio de abogados de la provincia de Buenos Aires, "Desde el Mercosur hacia la Patria Grande", La Plata 15-17 de abril, http://www.colproba.org.ar/mercosur/3.asp.

Nurske, Ragnar (1955), Problemas de formación del capital, Fondo de Cultura Económica, México. 
Ocampo, José (1998), “Cincuenta años de la CEPAL”, Revista de la CEPAL, núm. extraordinario, Santiago, pp. 11-16, http:// www.eclac.org/publicaciones/xml/1/19371/ocampo.htm

ONU (Organización de las Naciones Unidas) (1970), Estudio económico para América Latina, 1953 hasta el presente, ONU, México.

Orlansky, Dora (2006), "El concepto de desarrollo y las reformas estatales: visiones de los '90", Revista Documentos y Aportes, 6, Facultad de Ciencias Económicas, Universidad Nacional de Luján, Buenos Aires, pp. 1-20.

Página 12, (2009), "La pequeña Biblia de la Crisis. Fidel Castro presentó de puño y letra un texto sobre la crisis mundial que recibió del politólogo argentino Atilio Boron, a quien también recibió", 10 de marzo, http://www.pagina12. com.ar/diario/elmundo/4-121232-2009-03-10.html.

Palma, José (1987), "Dependencia y desarrollo: una visión crítica", en Dudley Seers (comp.), Teoría de la dependencia. Una reevaluación crítica, Fondo de Cultura Económica, México, pp. 21-89.

Perfil (2009), "La UIA no quiere a Chávez en el Mercosur y se pregunta qué hizo Kirchner con los fondos de Santa Cruz", 27 de mayo, http://www.perfil.com/contenidos/ 2009/05/27/noticia_0013.html.

Petras, James (2009), “¿Qué van a proteger cuando la gran mayoría de las multinacionales tienen sus principales ganancias en el exterior ahora, incluso en China?, 10 de febrero, http://www.rebelion.org/.

Pinto, Aníbal (2000), "Natureza e Implicações da Heterogeneidade Estrutural", Cinqüenta anos de pensamento na CEPAL, vol. 2, Récord-CEPAL, Río de Janeiro.

Prado Jr., Caio (1957), Esboço dos Fundamentos da Teoria Econômica, Editorial Brasiliense, San Pablo. 
Prado Jr., Caio (1968), La revolución brasileña, Peña Lillo, Buenos Aires.

Prebisch, Raúl (1962), "Reflexiones sobre la integración económica latinoamericana", Estado y Economía, año vi, 1, Facultad de Ciencias Económicas, Universidad Nacional de Córdoba, pp. 175-188.

Prebisch, Raúl (1965), "Informe sometido al Secretario General de las Naciones Unidas, U Thant, por el Dr. Raúl Prebisch, Secretario General de la Conferencia que se realizó en Ginebra del 23 de marzo al 16 de junio de 1964", El Trimestre Económico, XXXII (1), 125, Fondo de Cultura Económica, México, pp. 180-191.

Rofman, Alejandro (1993), "Estrategias alternativas frente al desafío del Mercosur”, en Pablo Ciccolella, María Victoria Fernández Caso, Elisa Laurelli y Alejandro Rofman (eds.), Modelos de integración en América Latina. Desafíos y alternativas en la construcción de un nuevo territorio latinoamericano, CEAL, Buenos Aires, pp. 47-137.

Rosales, Osvaldo (2006), "Integración regional: propuestas de renovación”, Seminario Internacional Paradojas de la Integración en América Latina, Santiago de Chile, 13-14 de diciembre, CEPAL-FLACSO-Fundación Carolina.

Schumpeter, Joseph (1965), Imperialismo y clases sociales, Tecnos, Madrid.

Schvarzer, Jorge (2001), "El Mercosur: un bloque económico con objetivos a precisar", en Jerónimo Sierra (comp.), Los rostros del Mercosur. El difícil camino de lo comercial a lo societal, CLACSO, Buenos Aires, pp. 21-43, http://biblioteca virtual.clacso.org.ar/ar/libros/sierra/schvarzer.pdf.

Sen, Sunanda (2005), "International Trade Theory and policy: what is left of the free trade paradigm?", Development and Change, 36 (6), Institute of Social Studies, Oxford, pp. 1011-1029. 
Subsecretaría de Industria, Gobierno de la Nación Argentina (2001), Inversión extranjera directa brasileña en la Argentina, http://www.industria.gov.ar/cep/cep_anteriores/notas/ notas $2 /$ nota10.htm, 5 de mayo.

Sunkel, Osvaldo (1998), "Desarrollo e integración regional: ‘̇otra oportunidad para una promesa incumplida?”, Revista de la CEPAL, núm. extraordinario, Santiago de Chile, pp. 229-241.

Sweezy, Paul (1973), Capitalismo e imperialismo norteamericano, Merayo, Buenos Aires.

Tamames, Ramón (1990), Estructura económica internacional, Alianza, Madrid.

Tamames, Ramón y Begoña Huerta (1999), Estructura económica internacional, Alianza, Madrid.

Tavares, María (1998), "La CEPAL y la integración de América Latina”, Revista de la CEPAL, núm. extraordinario, Santiago, pp. 213-218.

Teubal, Miguel (1973), "El fracaso de la integración económica latinoamericana”, en James Petras y Maurice Zeitlin (selecc.), América Latina: ¿̇eforma o revolución?, Tiempo Contemporáneo, Buenos Aires, pp. 117-142.

Thorp, Rose M. (2000), "Las economías latinoamericanas 1939c.-1950", en Leslie Bethell, Historia de América Latina. Economía y sociedad desde 1930, t. XI, Crítica, Barcelona, pp. 47-82.

Torrent, Ramón (2006), "Papel en los procesos de integración y concertación de actores externos: la UE, EE.UU. y Asia y actores internos: parlamentarios, sociedad civil y grupos empresariales", Seminario Internacional Paradojas de la Integración en América Latina, 13-14 de diciembre, CEPAL-FLACSO-Fundación Carolina, Buenos Aires.

Toussaint, Eric (2007), "Sobre las circunstancias que afectan a la creación del Banco del Sur", Rebelión, http://www. rebelion.org/noticia.php?id=51176, 9 de junio de 2007. 
Tugendhat, Charles (1973), Las empresas multinacionales, Alianza, Madrid.

Unión Panamericana, oEA (1964), El régimen de las inversiones privadas en el Mercado Común Centroamericano y en la Asociación Latinoamericana de Libre Comercio, OEA, Washington.

Vaillant, Marcel (2007), "Convergencias y divergencias en la integración sudamericana", Series CEPAL Comercio Internacional, 83, CEPAL, agosto, Santiago de Chile, http:// www.eclac.org/publicaciones/xml/7/30047/S83CI_ L2777e_P_Convergencias_divergencias_integracion_ sudamericana.pdf.

VTV (Venezolana de Televisión) (2007), “Lula invita a países africanos a producir biocombustibles para garantizar soberanía económica”, 16 de octubre, http://vtv.gov.ve/noticiasinternacionales/4046.

Verbitsky, Horacio (2009), "La supuesta 'argentinidad' del grupo Techint”, 31 de mayo, Mercosur Noticias, http:// www.mercosurnoticias.com/index.php? option $=$ com_content\&task $=$ view $\&$ id $=25122 \&$ Itemid $=30$.

Waldman, Peter (1983), Ensayos sobre politica y sociedad en América Latina, Alfa, Barcelona.

Wright Mills, Charles (1978), La élite del poder, Fondo de Cultura Económica, México.

Zibechi, Raúl (2007), "Estados Unidos y Brasil: la nueva alianza etanol", http://www.wrm.org.uy/temas/Biocombustibles/ Alianza_Etanol.html.

Recibido: 20 de febrero de 2008 . Aceptado: 8 de junio de 2009 . 
Silvina María Romano. Es licenciada en historia y licenciada en comunicación social por la Universidad Nacional de Córdoba; actualmente cursa el doctorado en ciencia política en el Centro de Estudios Avanzados de la Universidad Nacional de Córdoba. Es becaria del Consejo Nacional de Investigaciones Científicas y Tecnológicas (Conicet) e integrante del Grupo de Trabajo de Estudios sobre Estados Unidos de Clacso. Sus líneas de investigación son: procesos de integración en América Latina, relaciones entre Estados Unidos y América Latina durante las primeras décadas de la Guerra Fría, democracia liberal y seguridad nacional en Estados Unidos. Sus tres últimas publicaciones: "La Organización de Estados Americanos y la política exterior norteamericana frente América Latina en las primeras décadas de la Guerra Fría”, Enfoque social. Revista de Historia, Política y Sociedad, 3, Universidad Autónoma de Tamaulipas, México, pp. 61-95, (2008); "La integración económica latinoamericana y las relaciones político-económicas con Estados Unidos (1960-1973). Antecedentes del ALCA y el Mercosur", Programa Regional de Becas Clacso-ASDi 2005, http://bibliotecavirtual.clacso.org.ar/ar/libros/becas/2005/alcajov/ romano.pdf (2007); "América Latina y la política de seguridad norteamericana: continuidades”, Cuaderno de Trabajo, 13, Centro Argentino de Estudios Internacionales (CAEI) (www.caei.com.ar) (2006). 